\title{
A Study on the Relationships between Water Film Thickness, Fresh Properties, and Mechanical Properties of Cement Paste Containing Superfine Basalt Powder (SB)
}

\author{
Hengrui Liu ${ }^{1}$, Zhenghong Tian ${ }^{1,2}$ and Haoyue Fan ${ }^{1, *}$ \\ 1 College of Water Conservancy and Hydropower Engineering, Hohai University, Nanjing 210098, China; \\ 171302020037@hhu.edu.cn (H.L.); zhtianhhuu@163.com (Z.T.) \\ 2 State Key Laboratory of Hydrology Water Resources and Hydraulic Engineering, Hohai University, \\ Nanjing 210098, China \\ * Correspondence: 190802020003@hhu.edu.cn; Tel.: +86-188-5200-0661
}

Citation: Liu, H.; Tian, Z.; Fan, H. A Study on the Relationships between Water Film Thickness, Fresh

Properties, and Mechanical Properties of Cement Paste Containing Superfine Basalt Powder (SB). Materials 2021, 14, 7592. https:// doi.org/10.3390/ma14247592

Academic Editor: Luigi Coppola

Received: 12 November 2021

Accepted: 7 December 2021

Published: 10 December 2021

Publisher's Note: MDPI stays neutral with regard to jurisdictional claims in published maps and institutional affiliations.

Copyright: () 2021 by the authors. Licensee MDPI, Basel, Switzerland. This article is an open access article distributed under the terms and conditions of the Creative Commons Attribution (CC BY) license (https:// creativecommons.org/licenses/by/ $4.0 /)$.

\begin{abstract}
In this paper, the effect of a newly developed superfine basalt powder (SB) on the fresh and mechanical properties of cement paste was studied. The concept of water film thickness (WFT) was cited to explain the influence of SB on fresh and mechanical properties and related mathematical model formulas were established. In addition, the relationship between the fresh properties and mechanical properties of paste was also explored. The results indicated that SB can improve the segregation resistance and cohesiveness. The maximum improvement rate relative to the control cement paste was $75.4 \%$ and $50.4 \%$, respectively. The 5\% SB and 10\% SB reduced the fluidity in the range of $4.1-68.7 \%$ but increased the early and late compressive strength in the range of $1.2-25.7 \%$ compared to control cement paste under different water/cementitious materials (W/CM) ratios. However, the influence of $20 \%$ SB on fluidity and compressive strength was opposite to the above behavior, and the increase rate and decrease rate were $1.8-11.8 \%$ and $1.1-13.9 \%$ respectively. The WFT was the most important factor that determined the compressive strength, rheological parameters, and flow parameters of paste containing SB, while the substitute content of SB and WFT together determined the bleeding rate and cohesiveness. Among them, the correlation between bleeding rate and WFT increased with time. The empirical mathematical models between WFT, fresh properties, and compressive strength were established and verified by other mineral admixtures, which were successfully extended and applied to the entire field of cement-based materials.
\end{abstract}

Keywords: superfine basalt powder (SB); water film thickness (WFT); fresh properties; compressive strength; mathematical empirical model

\section{Introduction}

Cement has become the most common building material in engineering with the increasing global demand for construction, but the manufacturing process of cement causes serious environmental pollution and energy consumption [1-3]. Therefore, the development of green supplementary cementitious materials has been the focus of research in the field of cementitious materials, which can improve the performance of mixtures while saving costs and protecting the environment [4,5]. In recent years, some supplementary cementitious materials (SCM), such as silica powder, fly ash, zeolite, and limestone powder, have been used to substitute part of cement, but it is far from meeting the actual requirements of engineering applications [6-10]. It is a meaningful and promising topic to develop new green supplementary cementitious materials in the field of engineering construction.

Basalt has been used in engineering as a new type of cementitious materials due to its good properties. Weidong et al. [11] found that stone matrix asphalt (SMA) mixtures containing basalt coarse aggregate and fine aggregate had good rutting resistance, but poor resistance to cracking and moisture susceptibility. Dobiszewska et al. [12] reported 
that mixing basalt powder into concrete can improve flexural and compressive strength. P.P. Li et al. [13] found that coarse basalt aggregates slightly reduce the mechanical properties of UHPC. Ponzi [14] used basalt powder (BP) to Carbon Capture and Storage (CCS) wells, proving that low BP content and high water-binder ratio can improve the paste's resistance to $\mathrm{CO}_{2}$ degradation, reduce low porosity, and provide suitable mechanical properties. Matykiewicz [15] reported that increasing the replacement content of basalt powder can improve the thermomechanical properties of epoxy composites. Laibao et al. [16] proved through microscopic tests that basalt powder can consume calcium hydroxide in cement paste and has good pozzolanic reactivity. Moreover, the basalt powder also increases the consistency and retardation time. Saraya [17] also found that basalt powder had low pozzolanic activity in the early stage and increased with time, and that the improvement effect of basalt powder on the mechanical and physical properties was better than that of limestone. Kostrzewa-Demczuk [18] found that, in autoclaved bricks, the sample containing $10 \%$ basalt powder and $10 \%$ water has high compressive strength, high sealing performance, and medium water absorption, which meets the requirements of wall construction materials. The above results indicate that there are many studies on the microscopic and mechanical properties of basalt powder, but there has been little exploration on the fresh properties of basalt powder. The study of fresh properties is particularly important in cement-based applications, such as self-compacting concrete and grout materials, where excellent rheological properties are a prerequisite for effective application of paste. In addition, the adhesiveness and segregation resistance of basalt powder to paste also need to be studied.

The water film thickness (WFT) is an effective means to characterize fresh properties. The mechanism of WFT is to quantitatively characterize the surface effect and filling effect of the material simultaneously, which indirectly represents the particles' spacing [19]. Since the added water must first fill the voids between the solid particles, and the water in the voids cannot be used for lubrication, the fluidity of the paste can be effectively increased only by exceeding the free water required to fill the voids. The ultra-fine mineral admixtures can effectively reduce the voids of the mixture, which indicates that more free water can be used for lubrication to enhance fluidity. At the same time, the addition of ultrafine admixtures increases the specific surface area, requiring more free water to coat the particles. The WFT is a manifestation of the net effect of particle filling and surface effects. WFT has been gradually applied in the field of cement-based materials in recent years, and the relationship between WFT and the fresh properties has been established in different scenarios [20-25]. Therefore, in this paper, WFT was used to characterize the fresh properties of cement paste containing ultrafine basalt powder. In addition, the relationship between the different fresh properties were also explored.

In this paper, the fresh properties of cement paste containing a newly processed superfine basalt (SB) were explored, and the WFT is used to characterize the effect of SB on the fresh properties. The following four points were the main contributions of this paper:

(1) The effects of SB on the macroscopic fluidity, microscopic rheology, segregation resistance, cohesiveness and compressive strength of paste were studied.

(2) The influence of WFT on the fresh properties was studied, and related mathematical models were established.

(3) The relationships between different fresh properties of cement paste containing SB were also explored, and related mathematical models were established.

(4) The mathematical models established were verified in other mineral admixtures, providing theoretical guidance for the application of mineral admixtures in cement-based materials.

\section{Materials and Methods}

\subsection{Materials}

Two types of cementitious materials were used in this study: superfine basalt powder (SB) (Beijing Basalt Stone Material Factory, Hebei, Baoding, China) and ordinary Portland 
cement (OPC) (Anhui Conch Cement Company, Anhui, Wuhu, China). The OPC with a strength grade of 42.5 was selected, which conforms to the Chinese standard GB175-2007. The SB was a mineral powder mined from the Chengde basalt vein and processed by ultrafine grinding. The chemical composition of SB and OPC is given in Table 1. The composition of $\mathrm{SiO}_{2}, \mathrm{Al}_{2} \mathrm{O}_{3}$, and $\mathrm{Fe}_{3} \mathrm{O}_{4}$ in $\mathrm{SB}$ was more than $70 \%$, which has a good volcanic ash effect. The $\mathrm{SB}$ met the requirements of mineral admixtures for use in the field of cement-based materials according to ASTM C 618. The particle size distribution of SB and OPC is shown in Figure 1. The particle sizes of SB and OPC are $6.4 \mu \mathrm{m}$ and $14.5 \mu \mathrm{m}$, respectively. The specific surface area corresponding to $\mathrm{SB}$ and OPC was calculated to be $649.5 \mathrm{~m}^{2} / \mathrm{kg}$ and $367.9 \mathrm{~m}^{2} / \mathrm{kg}$, respectively. Figure 2 presents the Scanning Electron Microscope (SEM) (Carl Zeiss AG, Oberkochen, Germany) photography of SB. The SB had an irregular prismatic shape and did not have a lubricating effect. It mainly affected the mechanical and fresh properties of paste through filling effects and surface effects.

Table 1. Chemical compositions of OPC and SB used in the experiment.

\begin{tabular}{ccc}
\hline & \multicolumn{2}{c}{ Mass Percentage (\%) } \\
\cline { 2 - 3 } Phase & OPC & SB \\
\hline $\mathrm{SiO}_{2}$ & 13.9 & 46.59 \\
$\mathrm{Al}_{2} \mathrm{O}_{3}$ & 3.05 & 14.17 \\
$\mathrm{Fe}_{2} \mathrm{O}_{3}$ & 4.80 & 14.91 \\
$\mathrm{CaO}$ & 72.37 & 10.25 \\
$\mathrm{MgO}$ & 1.07 & 4.875 \\
$\mathrm{Na}_{2} \mathrm{O}$ & 0.16 & 4.26 \\
$\mathrm{SO}_{3}$ & 2.63 & 0.09 \\
$\mathrm{~K}_{2} \mathrm{O}$ & 0.97 & 1.55 \\
$\mathrm{P}_{2} \mathrm{O}_{5}$ & 0.23 & 0.64 \\
$\mathrm{TiO}_{2}$ & 0.35 & 2.34 \\
$\mathrm{MnO}_{\mathrm{ZrO}}$ & 0.30 & 0.18 \\
$\mathrm{SrO}^{\mathrm{Cl}}$ & 0.02 & 0.06 \\
& 0.10 & 0.04 \\
\end{tabular}

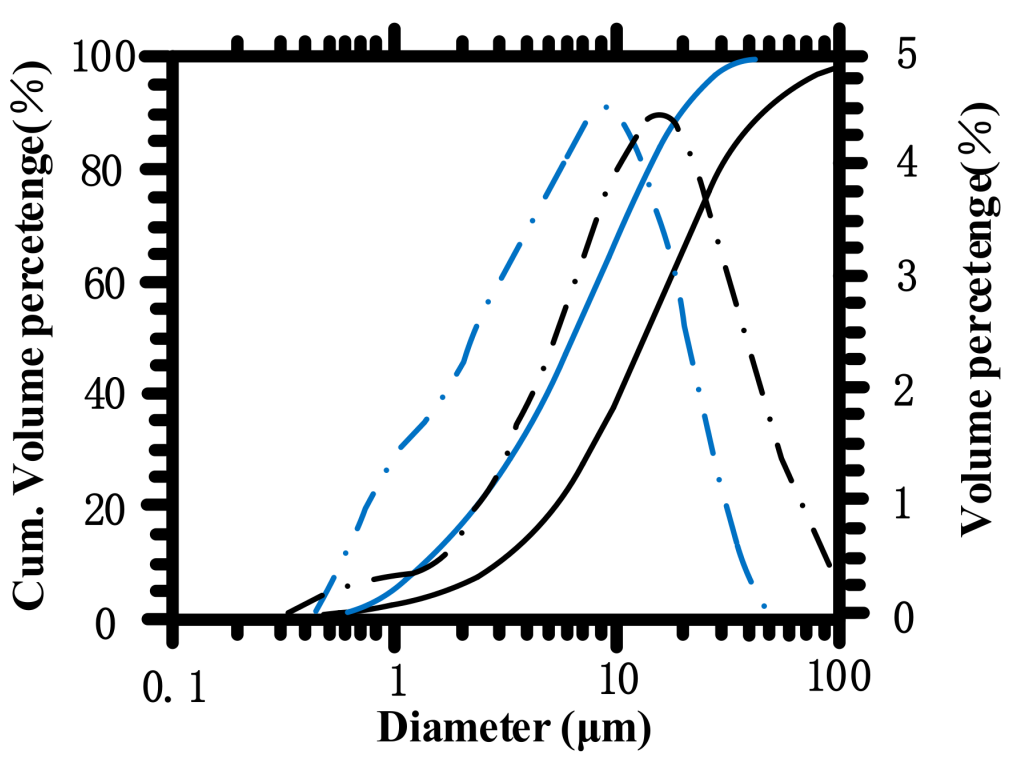

Portl and Cem. (D10=2.98 $\mu \mathrm{m}, \mathrm{D} 50=14.5 \mu \mathrm{m}, \mathrm{D} 90=49.18 \mu \mathrm{m})$ Basalt Powder. (D10 $=1.35 \mu \mathrm{m}, \mathrm{D} 50=6.4 \mu \mathrm{m}, \mathrm{D} 90=19.62 \mu \mathrm{m})$

Figure 1. Particle size distributions of OPC and SB. 


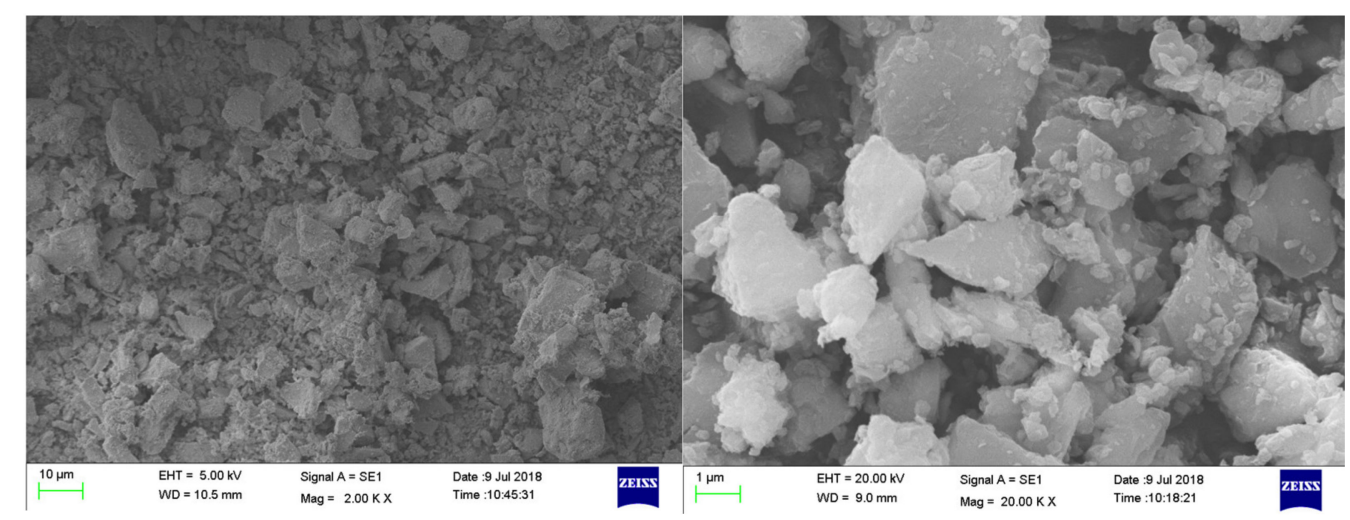

Figure 2. SEM morphology of SB.

\subsection{Experiment Plan}

In this study, SB replaced cement with $5 \%, 10 \%$, and $20 \%$ mass percentages, and the properties were tested at water/cementitious materials (W/CM) ratios of $0.5,0.55,0.6$, 0.65 , and 0.7 , respectively. The properties tested include void ratio, packing density, water film thickness (WFT), flow rate, flow spread, apparent viscosity, yield stress, bleeding rate, cohesiveness, and compressive strength. Since this was to investigate the effect of SB on the fresh properties and mechanical properties of paste, no superplasticizer was added here in order to avoid confusion. All experimental tests were performed in a laboratory at $20 \pm 1{ }^{\circ} \mathrm{C}$ and a humidity of $70 \%$.

\subsection{Test Methods}

\subsubsection{Flow Rate and Flow Spread}

Marsh cone (Tianjin Changji Testing Instrument Technology Company, TianJin, China) and mini-slump cone (Tianjin Changji Testing Instrument Technology Company, TianJin, China) were used to test the fluidity of cement paste. The mini slump cone version proposed by Ouchi and Okamura [26] was used to test the flow spread. The mini-slump cone had a top diameter of $70 \mathrm{~mm}$, a bottom diameter of $100 \mathrm{~mm}$, and a height of $60 \mathrm{~mm}$. The flow rate was measured by the marsh cone test according to the JC/T 1083-2008 standard.

\subsubsection{Yield Stress and Apparent Viscosity}

The NXS-11A coaxial rotational viscometer (Shanghai Precision Instrument Company, Shanghai, China) was used to measure the apparent viscosity and yield stress of cement paste [27]. Based on the interval of rheological parameters tested, it was necessary to use both the A system and the B system of the viscometer to conduct the test. The diameter and height of the rotors of the A system were $3.8 \mathrm{~cm}$ and $7 \mathrm{~cm}$, while the diameter and height of the rotor of the B system were $3.1 \mathrm{~cm}$ and $5 \mathrm{~cm}$, and the diameter of the outer cylinder was $4 \mathrm{~cm}$. Through System A and System B, the corresponding shear stress of paste at different shear rates can be measured. Here, the improved Bingham model was used to fit the test data points, and the apparent viscosity and yield stress can be obtained. According to the Equation (1):

$$
\tau=\tau_{0}+\mu \times \gamma+c \times \gamma^{2}
$$

where $\gamma$ is the shear rate, $\mu$ is the apparent viscosity, $\tau_{0}$ and $\tau$ are yield stress and shear stress, respectively.

\subsubsection{Cohesiveness}

The cohesiveness of the cement slurry was tested by the mini-sieve separation experiment [28]. The sieve mesh (Anping Youdun Metal Wire Mesh Products Company, Hebei, Anping County, China) used in this study has an aperture of $0.6 \mathrm{~mm}$. First, the mass of the 
sieve and the mass of the beaker (Anping Youdun Metal Wire Mesh Products Company, Hebei, China) used to receive the cement paste were measured, which were $m_{1}$ and $m_{2}$, respectively. About $400 \mathrm{~g}$ of cement paste was weighed into the beaker, and the beaker was slowly poured onto the sieve from a height of $300 \mathrm{~mm}$. Part of the cement paste can fall into the bottom beaker through the sieve. After the cement paste no longer dripped from the sieve, the mass of the sieve and the mass of the beaker were reweighed to $m_{3}$ and $\mathrm{m}_{4}$ respectively.

According to Equation (2), the sieve separation index (SSI) was defined as:

$$
\mathrm{SSI}=\left(\mathrm{m}_{4}-\mathrm{m}_{2}\right) /\left(\mathrm{m}_{3}-\mathrm{m}_{1}\right)
$$

The SSI is an indicator of cohesiveness of the paste. The cement paste with low cohesiveness can be dripped through the sieve, while it is difficult to drip through the sieve for the paste with high cohesiveness. Therefore, a lower SSI coefficient indicated that the paste had high cohesiveness.

\subsubsection{Bleeding Rate}

The cement paste was slowly poured into a $120 \mathrm{~mm}$ tall plexiglass container (Cangzhou Senzhong Test Instrument Company, Hebei, Cangzhou, China). After the paste level rose to a height of about $100 \mathrm{~mm}$, the pouring was stopped, and the plexiglass bottle cap (Cangzhou Senzhong Test Instrument Company, Hebei, China) was sealed to prevent moisture changes. The initial surface height of the cement paste was recorded as $\mathrm{d}_{0}$. The height of the bleeding water surface after $1 \mathrm{~h}$ and $3 \mathrm{~h}$ was measured as $\mathrm{d}_{1}$ and $\mathrm{d}_{2}$, respectively. According to Equation (3), the $1 \mathrm{~h}$ and $3 \mathrm{~h}$ bleeding rate can be calculated by the following formula [27]:

$$
\sigma_{1 \mathrm{~h}}=\left(\mathrm{d}_{1}-\mathrm{d}_{0}\right) / 100 \sigma_{3 \mathrm{~h}}=\left(\mathrm{d}_{2}-\mathrm{d}_{0}\right) / 100
$$

\subsubsection{Compressive Strength}

The compressive strength was tested in accordance with the Chinese standard GB502042002 [29]. The cement paste was firstly poured into a $70.7 \mathrm{~mm} \times 70.7 \mathrm{~mm} \times 70.7 \mathrm{~mm}$ mold (Monshanghong Company, Shanghai, China) and vibrated for $5 \mathrm{~s}$, and then cured for 1 day in a normal temperature environment. After pouring for 1 day, the cement paste block was taken out and put into a curing room with a temperature of $20 \pm 1{ }^{\circ} \mathrm{C}$ and a humidity of $90 \%$ for curing. The compressive strength test was carried out after 1, 7, and 28 days respectively, and the value of the compressive strength was taken as the average of the test results of 3 cement paste blocks.

\subsubsection{Void Ratio, Packing Density and WFT}

The wet filling method proposed by Kwan $[30,31]$ was adopted to measure the void ratio and packing density of the mixture to calculate the WFT. The principle of the wet filling method is to find the maximum solid concentration of the cementitious material mixed with water as the packing density of the mixture. In this experiment, multiple cement pastes were prepared for each mixing ratio, which have the same solid particle mixing ratio but different $\mathrm{W} / \mathrm{CM}$ ratios. The test range of $\mathrm{W} / \mathrm{CM}$ ratio ranges from insufficient to sufficient to fill the voids between particles. The maximum solid concentration tested was taken as the packing density of the mixture.

After the void ratio and packing density were calculated, the water film thickness (WFT) can be calculated by the following formula:

$$
\begin{gathered}
\mu_{0}=\mu_{\mathrm{W}}-\mu_{\mathrm{s}} \times\left(1-\mu_{\mathrm{pd}}\right) / \mu_{\mathrm{pd}} \\
\mathrm{A}=\mathrm{A}_{0} \times \mathrm{R}_{0}+\mathrm{A}_{\mathrm{B}} \times \mathrm{R}_{\mathrm{B}} \\
\mathrm{WFT}=\mu_{0} / \mathrm{A}
\end{gathered}
$$


where $\mu_{\mathrm{pd}}$ is the packing density of particles, $\mu_{\mathrm{s}}$ is the volume of solid particles, and $\mu_{\mathrm{W}}$ is the volume of mixing water. $R_{0}$, and $R_{B}$ are the volumetric ratios of OPC and SB to the total solid volume, respectively. $A_{0}$ and $A_{B}$ are the specific surface areas of OPC and $\mathrm{SB}$, respectively.

\section{Results and Discussion}

\subsection{The Effect of WFT on Fresh Properties of Cement Paste Containing SB}

3.1.1. Void Ratio, Packing Density, and WFT

The packing density and void ratio results are plotted against the SB substitutions in Figure 3. The results showed that the packing density and void ratio of cement paste increased and decreased with increasing SB substitutions, respectively. This was attributed to the filling of SB particles. Since the size of SB was much smaller than that of cement particles, it can be filled into the voids to increase a solid concentration of the mixture. Among them, the filling effect of $20 \%$ SB was the most significant, with the void ratio reduced by $11.6 \%$ and the packing density increased by $5.77 \%$.

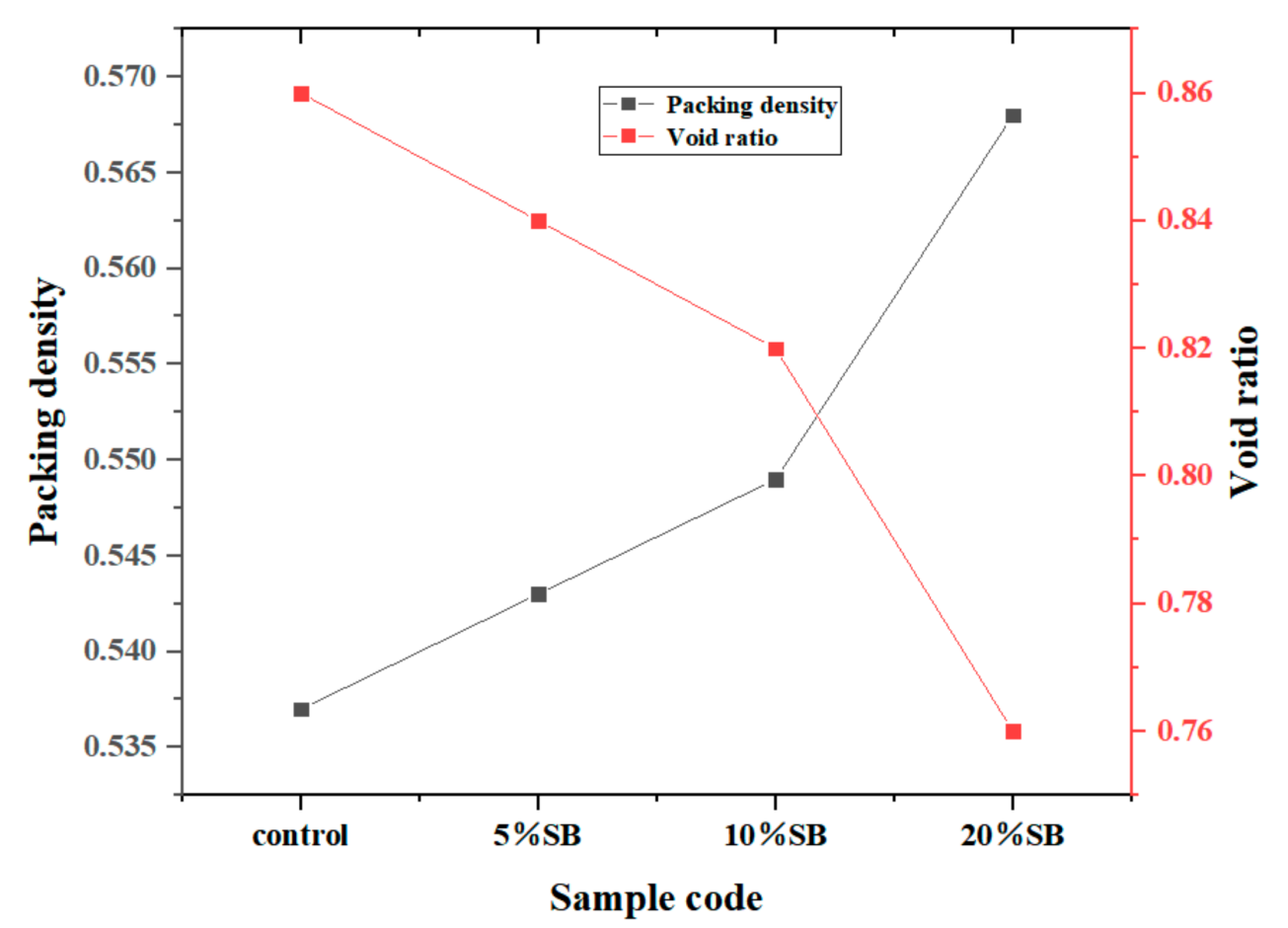

Figure 3. Variations of the void ratio and packing density at different SB substitutions.

At the same time, the incorporation of SB also significantly increased the specific surface area of the particles, requiring more free water to wrap on the surface of the particles. The WFT results are plotted against the SB substitutions for different $\mathrm{W} / \mathrm{CM}$ ratios in Figure 4. The WFT first decreased as the SB incorporation increased from $0 \%$ to $10 \%$, and then increased as the SB incorporation further increased from $10 \%$ to $20 \%$. This indicated that the net effects of SB particle filling and surface effects were negative at $5 \%$ and $10 \%$, which had an adverse effect on the fluidity of the cement paste. However, it was positive only when the SB incorporation was $20 \%$, which can play a lubricating effect and promote the fluidity of the paste. The relationship between the WFT and the fresh properties is investigated in detail below. 


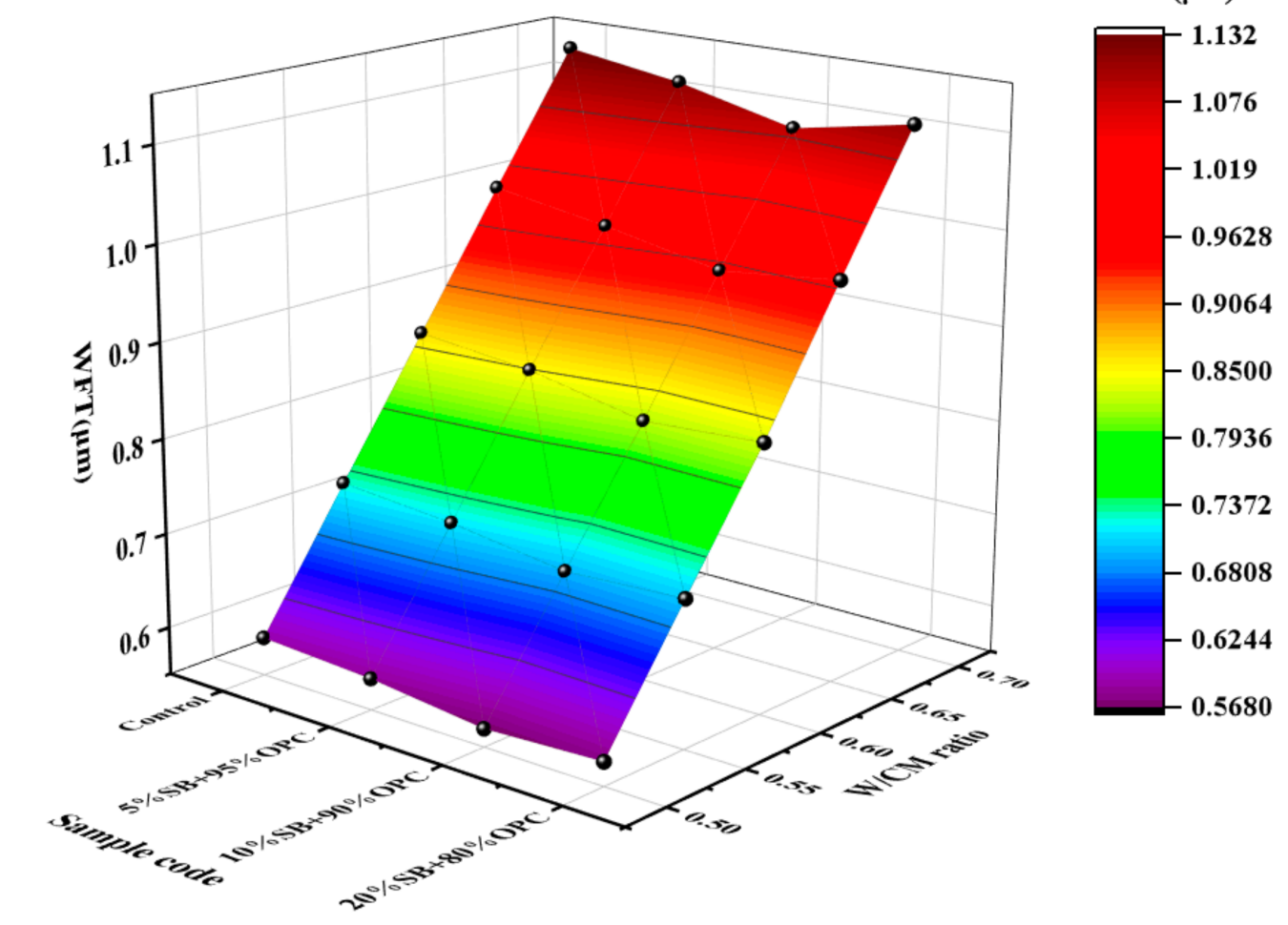

Figure 4. Variations of the WFT with W/CM ratio at different SB substitutions.

\subsubsection{Flow Spread and Flow Rate versus W/CM Ratio and WFT}

Figure $5 \mathrm{a}, \mathrm{b}$ presents the variations of the flow rate and flow spread with the W/CM ratio for different $\mathrm{SB}$ substitutions. The results indicated that the effect of $\mathrm{SB}$ on the fluidity of cement paste was greatly affected by the W/CM ratio. At a W/CM ratio equal to 0.5 , the incorporation of $\mathrm{SB}$ reduced the flow rate of cement paste. At a W/CM ratio equal to 0.7 , the flow rate of paste containing different $\mathrm{SB}$ substitutions was higher than the control. In the case of other $\mathrm{W} / \mathrm{CM}$ ratios, the flow rate first decreased as the $\mathrm{SB}$ incorporation increased from $0 \%$ to $10 \%$ and then increased as the SB incorporation further increased from $10 \%$ to $20 \%$. Relative to flow spread, the influence of SB on the flow rate was more regular with the $\mathrm{W} / \mathrm{CM}$ ratio. The flow spread exhibited the same phenomenon as the flow rate when the W/CM ratio was equal to 0.5 and 0.7 . The change in $\mathrm{W} / \mathrm{CM}$ ratio from 0.55 to 0.65 was more complicated. The flow spread of $10 \%$ SB was always lower than the control, while the flow spread of 5\% SB and 20\% SB increased from below the control to exceed the control with the increase of the $\mathrm{W} / \mathrm{CM}$ ratio.

To study the influence of WFT on flow rate and flow spread, regression analysis was performed to obtain the best fitting curve of the flow spread-WFT relationship and flow rate-WFT relationship. The flow rate and flow spread are shown as functions of the WFT in Figure 5c,d. The results indicated that the WFT, flow spread, and flow rate had excellent correlations, and $\mathrm{R}^{2}$ exceeded 0.9. WFT was the most critical factor to control the macro-fluidity of cement paste containing SB. The mechanism of WFT affecting the macro-fluidity of cement paste was mainly through the lubrication between particles. The increase in the WFT reduced the friction between the particles, which can improve the fluidity of the paste [32]. 


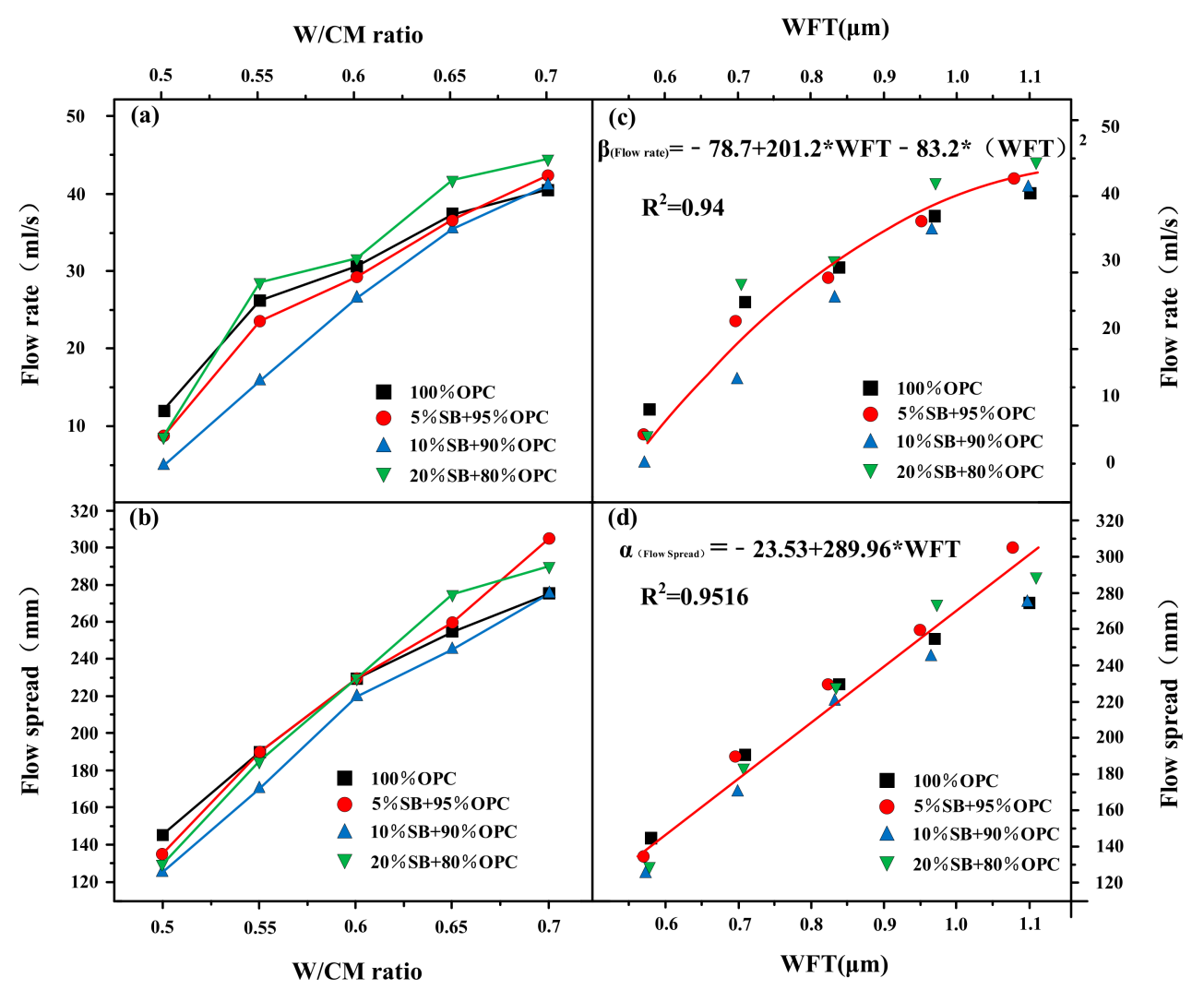

Figure 5. Flow rate and flow spread versus W/CM ratio $(\mathbf{a}, \mathbf{b})$ and WFT (c,d).

\subsubsection{Apparent Viscosity and Yield Stress W/CM Ratio Versus WFT}

Figure $6 \mathrm{a}, \mathrm{b}$ presents the variations of the apparent viscosity and yield stress with $\mathrm{W} / \mathrm{CM}$ ratio for different SB substitutions. The apparent viscosity and yield stress of $10 \% \mathrm{SB}$ at various $\mathrm{W} / \mathrm{CM}$ ratios were higher than the control, which was consistent with the variation rule of flow rate and flow spread. While the rheological parameters of $5 \% \mathrm{SB}$ and $20 \% \mathrm{SB}$ had complicated changes. When the $\mathrm{W} / \mathrm{CM}$ ratio was greater than 0.5 , the incorporation of $5 \% \mathrm{SB}$ and $20 \% \mathrm{SB}$ can reduce the apparent viscosity, but the decrease degree was extremely limited. For the yield stress, $5 \%$ SB and 10\% SB were higher than the control at different $\mathrm{W} / \mathrm{CM}$ ratios. The yield stress of $20 \% \mathrm{SB}$ at a W/CM ratio of $0.55-0.7$ were lower than the control.

Apparent viscosity and yield stress mainly reflected the internal microstructure of the paste. This microstructure was significantly affected by the particles spacing, and WFT can indirectly represent the particles spacing. SB mainly affected the apparent viscosity and yield stress of paste by changing WFT. For example, $10 \%$ SB significantly reduced WFT, and the reduction of the particles spacing made particles more prone to collision and friction, which enhanced the shear resistance of the paste and increased the rheological parameters.

The apparent viscosity and yield stress of paste containing SB were also significantly affected by the W/CM ratio. At a W/CM ratio equal to 0.5 , different substitutions of SB could increase the apparent viscosity and yield stress to varying degrees. The different substitutions of SB had a negative effect on the apparent viscosity and yield stress.

The increase of the W/CM ratio increased the WFT of the particles within the paste, that is, increased the particles' spacing. The rheological parameters of paste were mainly affected by colloidal attraction force, Brownian force, and gravity [33]. Among them, Brownian force and colloidal attraction force were closely related to particle spacing. The addition of SB can easily cause great changes in Brownian and colloidal gravitation at small particle spacing. On the contrary, the addition of SB had little effect on Brownian attraction and colloid attraction at large particle spacing. There was a threshold value of particle spacing affecting the rheological parameters [34]. When particle spacing exceeded this 
threshold, the ability of SB to influence rheological parameters of cement paste weakened. Therefore, the change of W/CM ratio can significantly affect the apparent viscosity and yield stress.

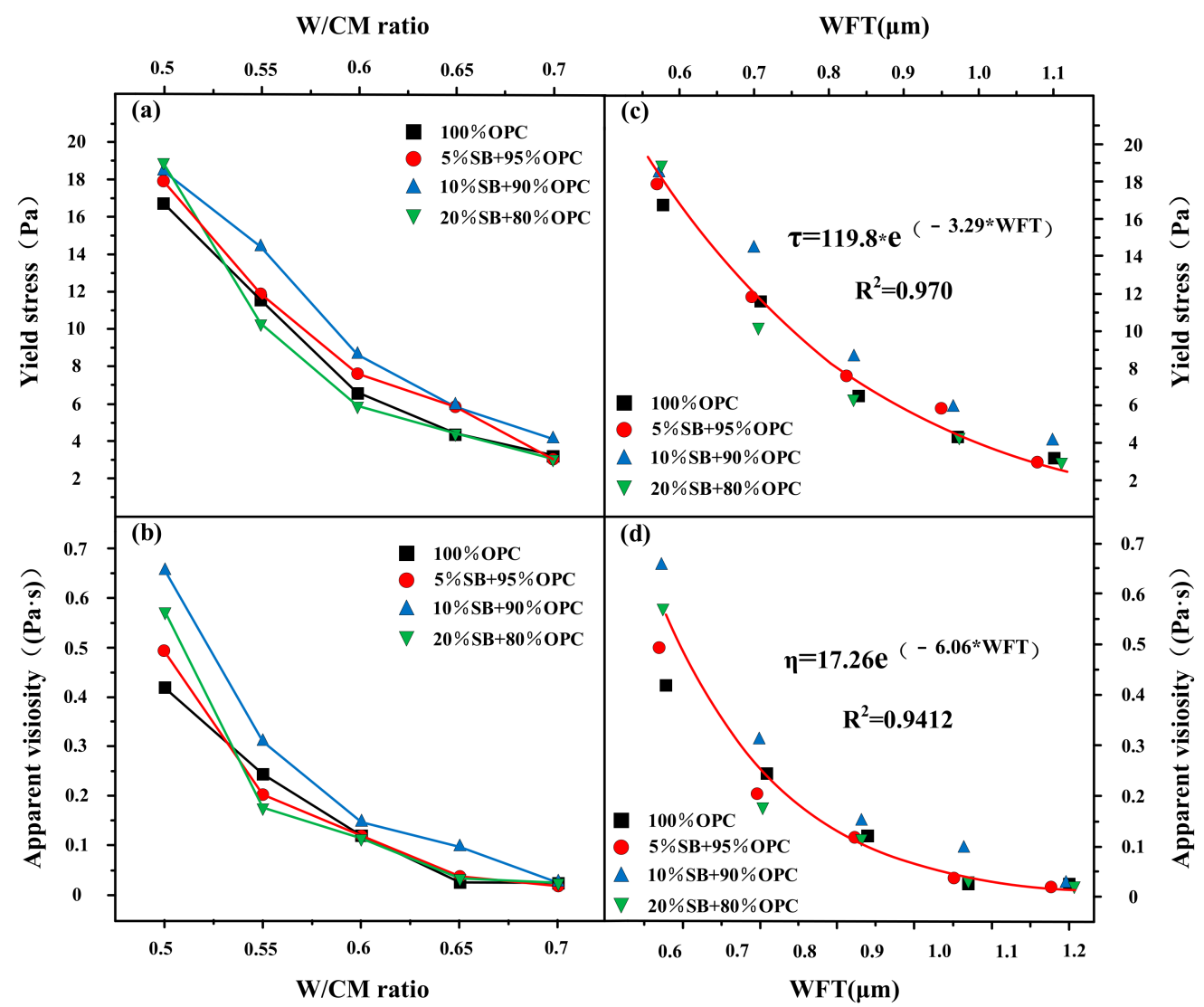

Figure 6. Yield stress and apparent viscosity versus W/CM ratio $(\mathbf{a}, \mathbf{b})$ and WFT $(\mathbf{c}, \mathbf{d})$.

The apparent viscosity and yield stress are shown as functions of the WFT in Figure $6 c, \mathrm{~d}$. It can be seen from the results that when the WFT was at a large value, SB had little influence on the rheological parameters of the paste. On the contrary, when the WFT was at a smaller value, SB plays a more significant role. Apparent viscosity and yield stress had excellent correlation with WFT, and both $\mathrm{R}^{2}$ values exceeded 0.94 . This verifies the above conclusions; SB mainly affected the apparent viscosity and yield stress by influencing WFT. The WFT played a key role in affecting the rheological parameters of cement paste containing SB.

\subsubsection{Cohesiveness Versus W/CM Ratio and WFT}

Figure 7a presents the variations of the cohesiveness with $\mathrm{W} / \mathrm{CM}$ ratio for different SB substitutions. The results showed that the SSI index decreased with the increase of SB substitution. The addition of SB increased the cohesiveness of cement paste. Especially when SB increased from $5 \%$ to $10 \%$, the cohesiveness increased significantly, but when SB was further increased from $10 \%$ to $20 \%$, the cohesiveness increased slightly.

Cohesiveness is shown as a function of the WFT in Figure $7 \mathrm{~b}$. According to the results, the cohesiveness of the paste increased with increasing SB substitutions at the same WFT. However, unlike the results of flow parameters and rheological parameters, the correlation between WFT and cohesiveness was extremely poor, and the dispersion degree of data points was very large, indicating that WFT was not the only factor determining cohesiveness. As can be seen from the fitting curve in Figure 7b, it was also related to the replacement contents of SB itself. 


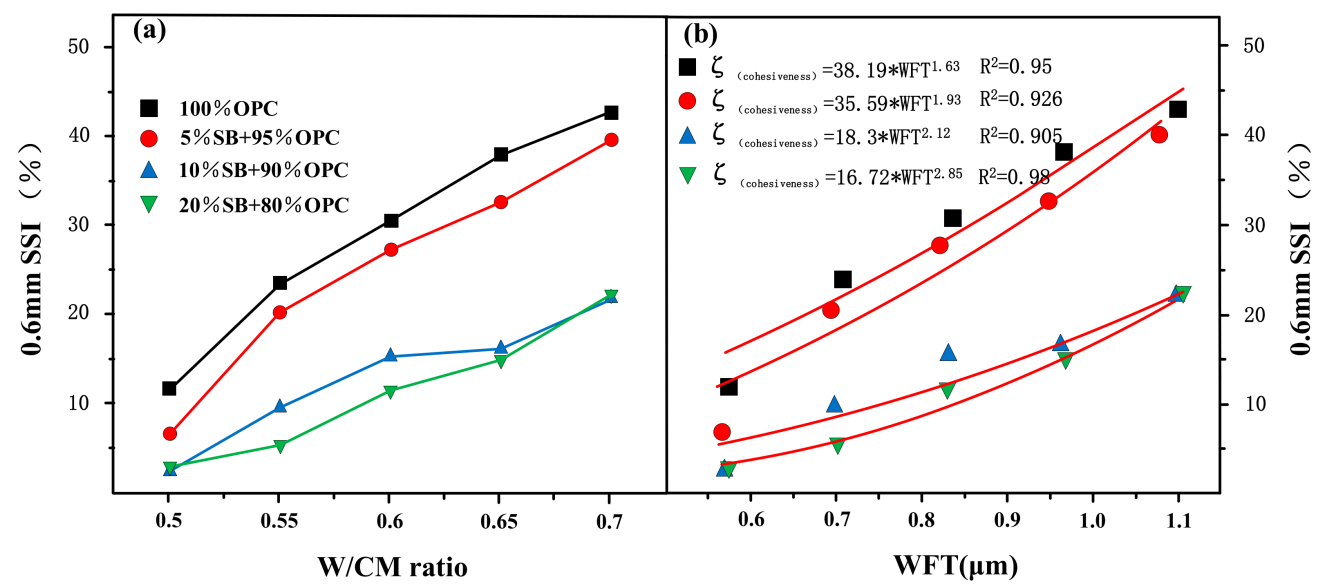

Figure 7. Cohesiveness versus W/CM ratio (a) and WFT (b).

Cohesiveness represents the bonding strength between particles, and is related to both physical and chemical factors. When the fine SB particles filled in the voids of the cement, the contact between the particles move closer together, thereby enhancing the cohesiveness. In addition, the high specific surface area of SB also increased the electrostatic attraction between particles, thereby increasing particle aggregation. The SB contains a high content of $\mathrm{SiO}_{2}$ and $\mathrm{Al}_{2} \mathrm{O}_{3}$, which consumed the $\mathrm{Ca}(\mathrm{OH})_{2}$ in the cement paste. Since crystalline $\mathrm{Ca}(\mathrm{OH})_{2}$ has a layered structure, the interlayer forces mainly depended on the hydrogen bonding between the oxygen atoms, and the binding forces were weak. However, the reduction of $\mathrm{Ca}(\mathrm{OH})_{2}$ content increases the bonding strength between the internal particles, which enhanced the cohesiveness of the paste [35]. The concept of WFT only considered the physical effects of SB, and did not consider the chemical effects caused by SB. Therefore, the WFT is not the only factor that determines the cohesiveness of the cement paste, but is also related to the substitute content of SB.

\subsubsection{Bleeding Rate versus W/CM Ratio and WFT}

Figure $8 \mathrm{a}, \mathrm{b}$ presents the variations of the $1 \mathrm{~h}$ and $3 \mathrm{~h}$ bleeding rate with $\mathrm{W} / \mathrm{CM}$ ratio for different SB substitutions. At $1 \mathrm{~h}, 10 \% \mathrm{SB}$ and $20 \% \mathrm{SB}$ reduced the bleeding rate of cement paste at various $\mathrm{W} / \mathrm{CM}$ ratios, while $5 \% \mathrm{SB}$ slightly increased the bleeding rate. At $3 \mathrm{~h}$, the reduction degree of the bleeding rate by SB further increased, and the bleeding rate of cement paste containing SB was lower than the control in almost all scenarios. At a $\mathrm{W} / \mathrm{CM}$ ratio equal to $0.5,10 \% \mathrm{SB}$ and $20 \% \mathrm{SB}$ were reduced by $0.06 \%$ and $0.1 \%$, respectively, based on the control. At a W/CM ratio equal to $0.7,10 \%$ SB and $20 \%$ SB were reduced by $2.8 \%$ and $5.61 \%$, respectively, based on the control. The above results indicated that the replacement of SB effectively reduced the bleeding rate of paste, especially in the case of high $\mathrm{W} / \mathrm{CM}$ ratio and high substitution.

SB reduces the bleeding rate due to the following reasons: (i) The density of SB particles is significantly lower than that of cement particles, and they are not easy to sink under the action of water resistance. (ii) SB increases the packing density of the paste, and the close packing of the internal structure effectively prevents the sinking of the particles. (iii) SB has a high content of $\mathrm{SiO}_{2}$ and $\mathrm{Al}_{2} \mathrm{O}_{3}$, which chemically reacted with $\mathrm{Ca}(\mathrm{OH})_{2}$ to further increase the flocculation structure and internal colloid network within the paste [36].

The $1 \mathrm{~h}$ and $3 \mathrm{~h}$ bleeding rate are shown as functions of the WFT in Figure 8c,d. Similar to cohesiveness, the bleeding rate had a poor correlation with WFT, and the bleeding rate was also affected by other parameters, such as the substitute content of SB. WFT is not the only factor that determines the bleeding rate of cement paste. In addition, it was found from the Figure $8 \mathrm{c}, \mathrm{d}$ that the regression coefficient $\mathrm{R}^{2}$ of WFT and the bleeding rate increased significantly from $1 \mathrm{~h}$ to $3 \mathrm{~h}$, because the WFT decreased with the increase of time, and the water wrapped on the particle surface broke away from the particle and entered into the bleeding area, while the particle gradually sank into the sediment zone. 


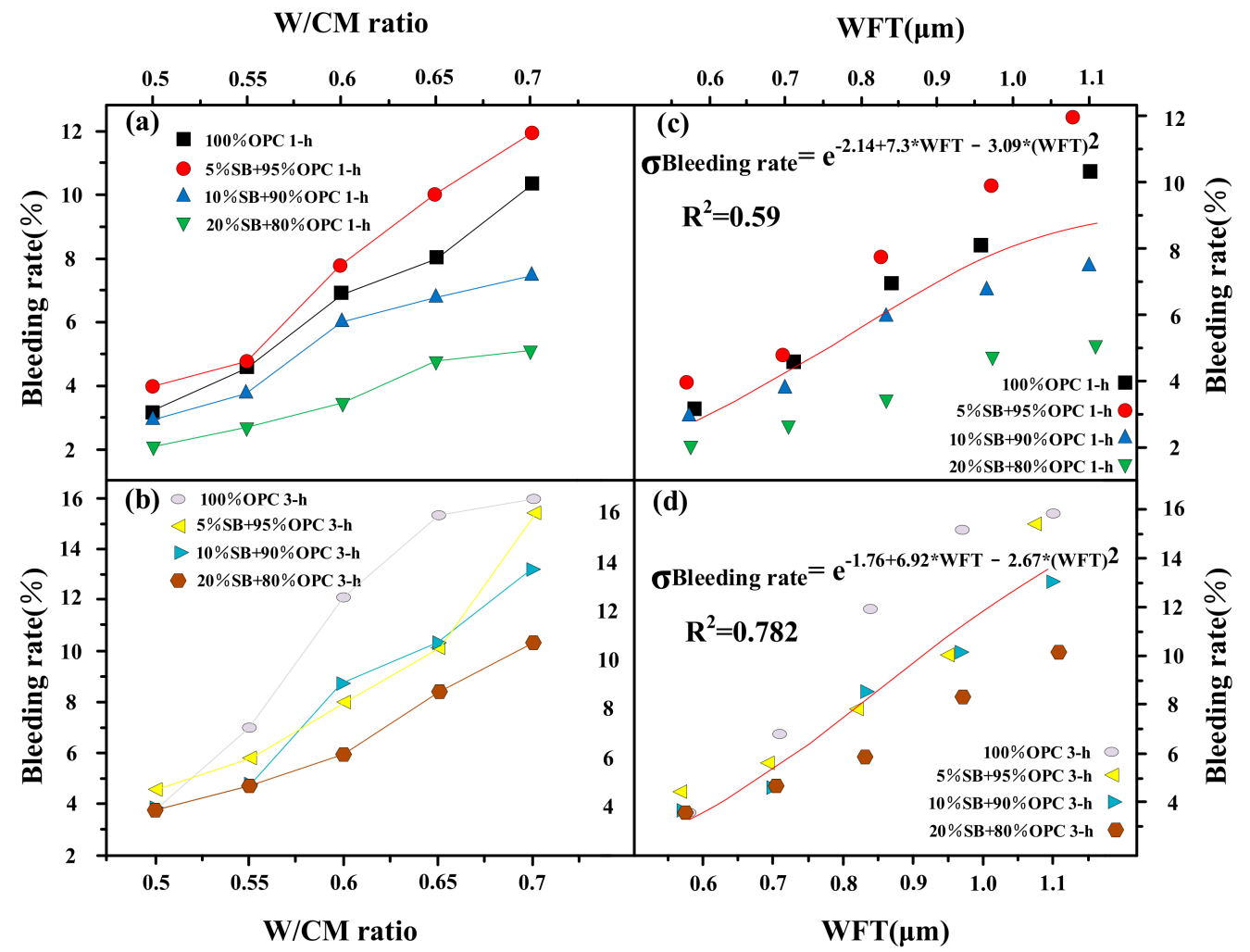

Figure 8. Bleeding rate versus $\mathrm{W} / \mathrm{CM}$ ratio $(\mathbf{a}, \mathbf{b})$ and $\mathrm{WFT}(\mathbf{c}, \mathbf{d})$.

\subsubsection{Compressive Strength versus W/CM Ratio and WFT}

Figure 9a presents the variations of the 1 day, 7 days, and 28 days compressive strength with the $\mathrm{W} / \mathrm{CM}$ ratio for different $\mathrm{SB}$ substitutions. From the results of compressive strength in different periods, both the $\mathrm{W} / \mathrm{CM}$ and the replacement content of SB can affect the compressive strength of paste. At 1 day, except for $5 \%$ SB which can improve the compressive strength at low $\mathrm{W} / \mathrm{CM}$ ratio, the influence of $\mathrm{SB}$ on the compressive strength of paste in other scenarios was not remarkable. At 7 days and 28 days, the difference in compressive strength of different cement paste samples began to appear. In general, 10\% SB and 5\% SB improved the compressive strength, while 20\% SB reduced the compressive strength, which showed the same law under all $\mathrm{W} / \mathrm{CM}$ ratios. With the increase of the $\mathrm{W} / \mathrm{CM}$ ratio, the ability of $\mathrm{SB}$ to influence the compressive strength was gradually weakened, and the performance of $\mathrm{SB}$ was more effective at low $\mathrm{W} / \mathrm{CM}$ ratio.

The influence of SB on the compressive strength of cement slurry was mainly attributed to three effects: inherent characteristics, grain refinement effect, and the hydration effect $[37,38]$. The inherent characteristics mainly refer to the surface structure and charge characteristics of the particles. When SB was in contact with the colloidal suspension, the inherent characteristics of SB affected the nucleation and growth of hydration products, thereby affecting the compressive strength of the cement paste. The grain refinement effect can affect the interface area between $\mathrm{SB}$ and hydration products, making the internal structure of the paste more compact and uniform. The hydration effect was that $\mathrm{SiO}_{2}$ and $\mathrm{Al}_{2} \mathrm{O}_{3}$ inside $\mathrm{SB}$ consume $\mathrm{Ca}(\mathrm{OH}) 2$ in paste and generate calcium silicate hydrate $(\mathrm{CSH})$. The structure between $\mathrm{SB}$ and the cement base was more compact, which effectively reduced the void ratio and improved the mechanical properties of the colloid interfacial area [39]. But at the same time, the replacement of SB also reduced the content of the cement, which reduced the generation of hydration products. As a result, the net effect of $5 \% \mathrm{SB}$ and $10 \%$ SB substitution was positive, while the net effect of $20 \%$ SB was negative.

The compressive strength of 1 day, 7 days, and 28 days are shown as functions of the WFT in Figure $8 \mathrm{~b}-\mathrm{d}$. The results show that the compressive strength of cement paste decreased with increasing WFT. The regression coefficient $R^{2}$ was $0.899,0.936$, and 0.927 at 
1 day, 7 days, and 28 days, respectively, indicating WFT and compressive strength have a good correlation. WFT is also the main factor that determines compressive strength because WFT can indirectly represent the distance between particles. The increase of particle spacing makes the internal structure of paste loose and increases the porosity between structures, thus reducing the mechanical properties of the colloid interface area.

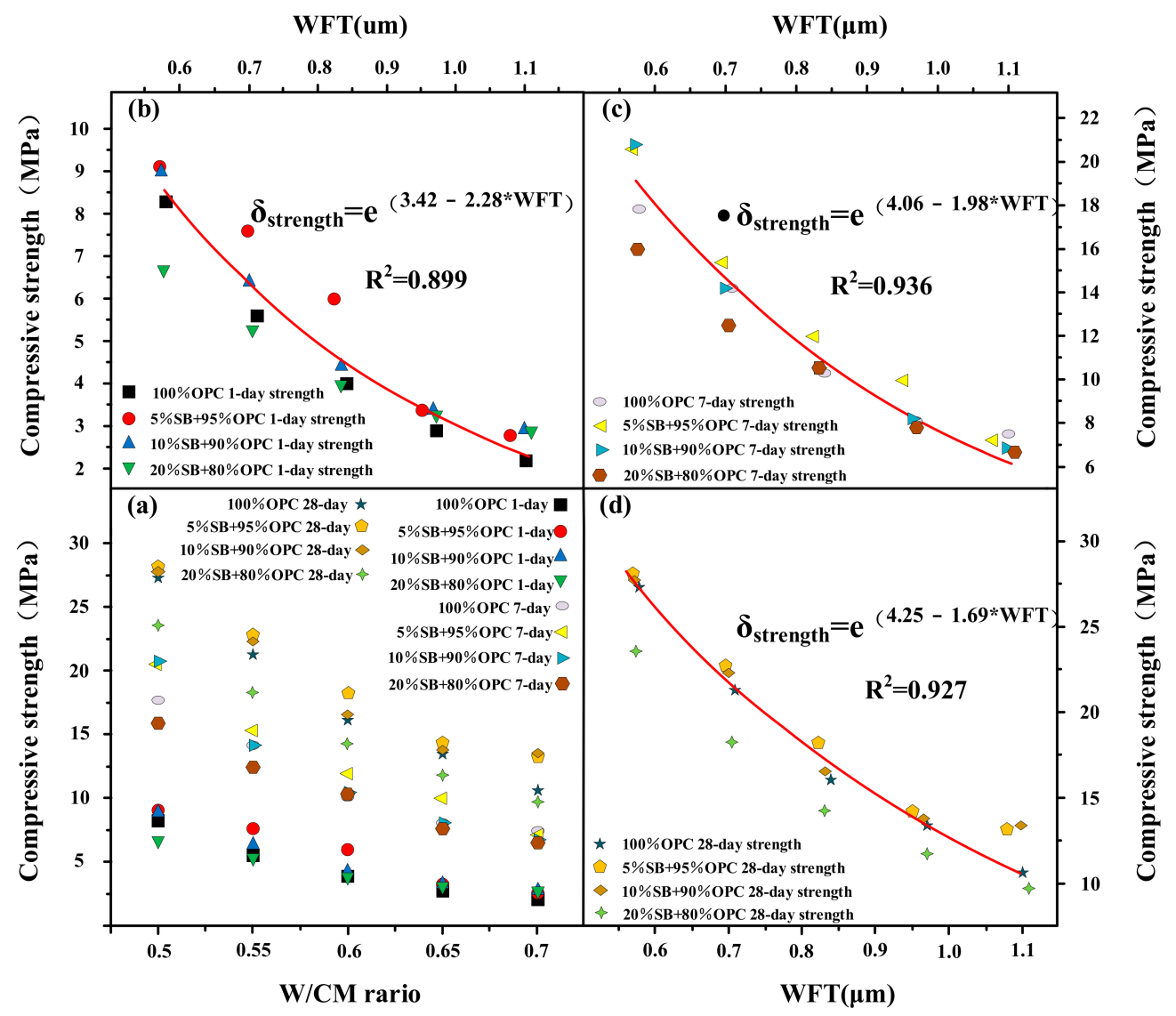

Figure 9. Compressive strength versus W/CM ratio (a) and WFT (b-d).

\subsection{The Relationships between Different Fresh Properties}

Section 3.1 explored the effects of SB on flow parameters, rheological parameters, cohesiveness, and bleeding rate of cement paste, and cited the concept of WFT to establish a relationship with these parameters. The mathematical models between WFT and these properties were established. This section establishes a connection between fresh properties and mechanical properties. There are two meanings of this. The relationship between the compressive strength and fresh properties of cement paste has been rarely explored so far. In addition, the empirical mathematical model with good correlation can provide references for other scholars.

The flow rate and flow spread and apparent viscosity and yield stress for SB substitutions from $5 \%$ to $20 \%$ in are shown in Figure $10 \mathrm{a}-\mathrm{d}$. The flow rate and flow spread decreased with increasing apparent viscosity and yield stress. There was a good correlation between rheological parameters and flow parameters, and the correlation coefficient $\mathrm{R}^{2}$ exceeded 0.95. The relationships between flow parameters and rheological parameters conformed to the following mathematical model: $\alpha_{\text {(Flow spread) }}=A+B^{*} \tau_{(\text {Yield stress) }}, \beta_{\text {(Flow rate) }}=A+$ $B^{*} \tau_{(\text {Yield stress })}, \alpha_{(\text {Flow spread })}=\mathrm{e}^{\left(\mathrm{A}+\mathrm{B}^{*} \eta(\text { Apparent viscosity })\right)}, \beta_{\text {(Flow rate })}=A \mathrm{e}^{\left(\mathrm{B}^{*} \eta(\text { Apparent viscosity })\right)}$. Flow rate and flow spread characterize the macroscopic fluidity, which is a direct manifestation of the dynamic and static flow of cement paste. The apparent viscosity and yield stress characterize the micro-rheological properties. The yield stress was the critical stress when the paste starts to flow, and the apparent viscosity was the ability of the internal 
structure to hinder the flow of the paste. Therefore, the yield stress and apparent viscosity can determine the flow rate and flow spread of the cement paste containing SB.

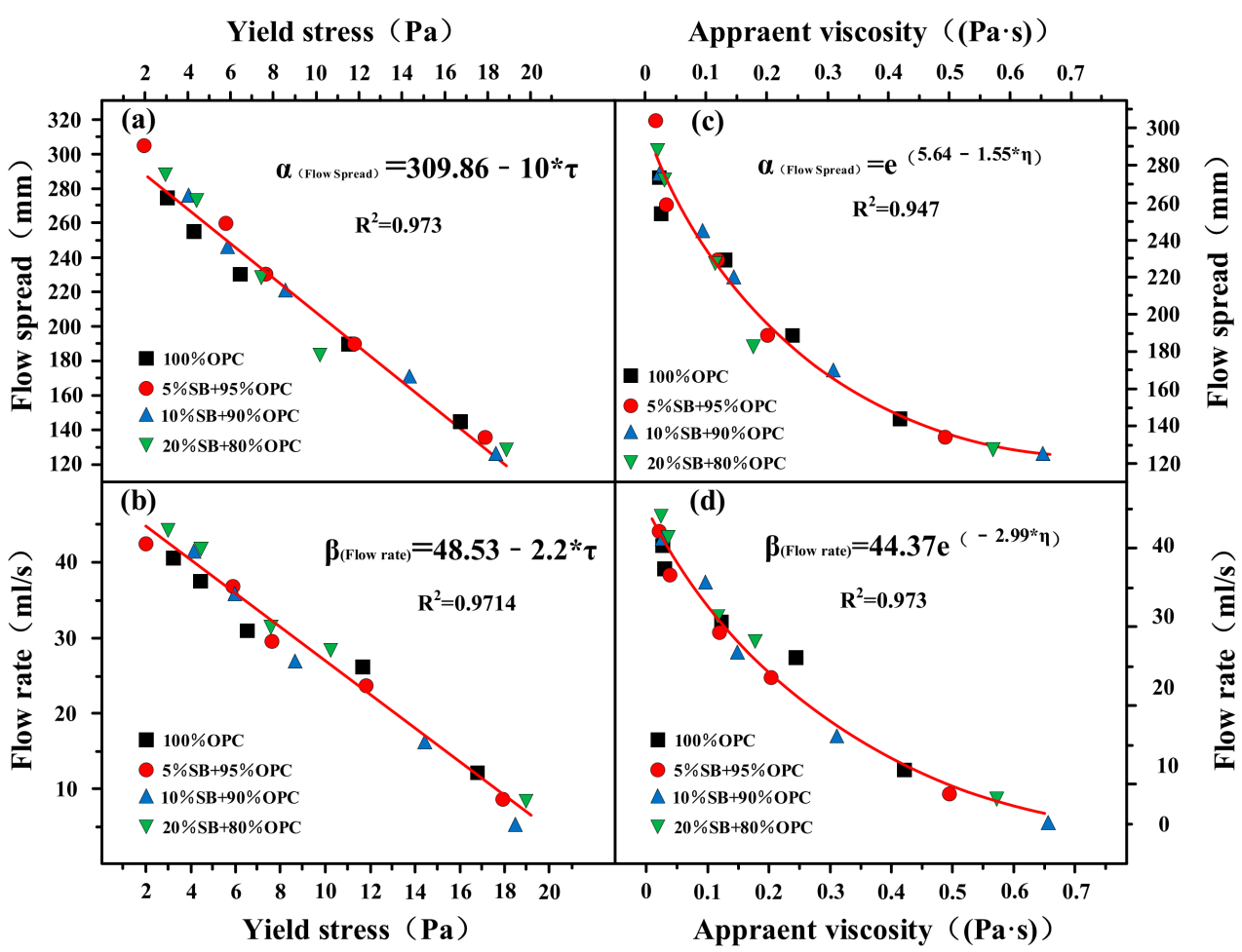

Figure 10. Flow rate and flow spread versus apparent viscosity $(\mathbf{c}, \mathbf{d})$ and yield stress $(\mathbf{a}, \mathbf{b})$.

The flow rate and flow spread are shown as functions of 1 day, 7 days, and 28 days of compressive strength for SB substitutions from 5\% to $20 \%$ in Figure 11 a-f. At 1 day, 7 days, and 28 days, compressive strength decreased with an increasing flow rate and flow spread. There was also a good correlation between compressive strength, flow rate, and flow spread. The relationship between flow parameters and compressive strength conformed to the following mathematical model: $\delta_{\text {(Compressive strength) }}=\mathrm{A}+\mathrm{B}^{*} \alpha_{\text {(Flow spread) }}$ and $\delta_{\text {(Compressive strength) }}=A+B^{*} \beta_{\text {(Flow rate) }}$. The flow parameters affected compressive strength mainly through the effect of WFT and exhibits the same behavior for apparent viscosity yield stress, as shown in Figure 12. The relationship between flow parameters and compressive strength conform to the following mathematical model: $\delta$ (Compressive strength) $=\mathrm{A}+\mathrm{B}^{*} \tau_{\text {(Yield stress) }}$ and $\delta_{(\text {Compressive strength) }}=\mathrm{A}^{*} \eta_{\text {(Apparent viscosity) }}{ }^{\mathrm{B}}$. At 1 day, 7 days, and 28 days, compressive strength increased with increasing apparent viscosity and yield stress. From the conclusions of the Section 3.1, it can be known that WFT was the most important factor in determining flow parameters and rheological parameters. Therefore, SB affected flow parameters and rheological parameters by influencing WFT. The change of WFT also affected the change of compressive strength, which was why the compressive strength had a good correlation with the rheological parameters and flow parameters.

The flow rate and flow spread are shown as functions of the bleeding rate for SB substitutions from $5 \%$ to $20 \%$ in Figure $13 \mathrm{a}-\mathrm{d}$. The results showed that flow rate and flow spread increased with the increase of bleeding rate. However, the correlations between flow parameters and bleeding rate were poor. There were rheological parameters with the same behavior, as shown in Figure 14. Among them, the regression coefficient $R^{2}$ was between the bleeding rate and rheological parameters, and the flow parameters significantly improved from $1 \mathrm{~h}$ to $3 \mathrm{~h}$. This phenomenon was similar to the relationship between the bleeding rate and WFT.

The flow rate, flow spread, apparent viscosity, and yield stress are functions of the cohesiveness for SB substitutions from 5\% to $20 \%$ in Figure 15a-d. The flow parameters 
decreased with the increase of cohesiveness, and the rheological parameters increased with the increase of cohesiveness. Neither flow parameters nor rheological parameters were the only factors that determine cohesiveness, but are also related to the substitute content of SB.

Flow spread $(\mathbf{m m})$

Flow spread $(\mathbf{m m})$

Flow spread $(\mathbf{m m})$

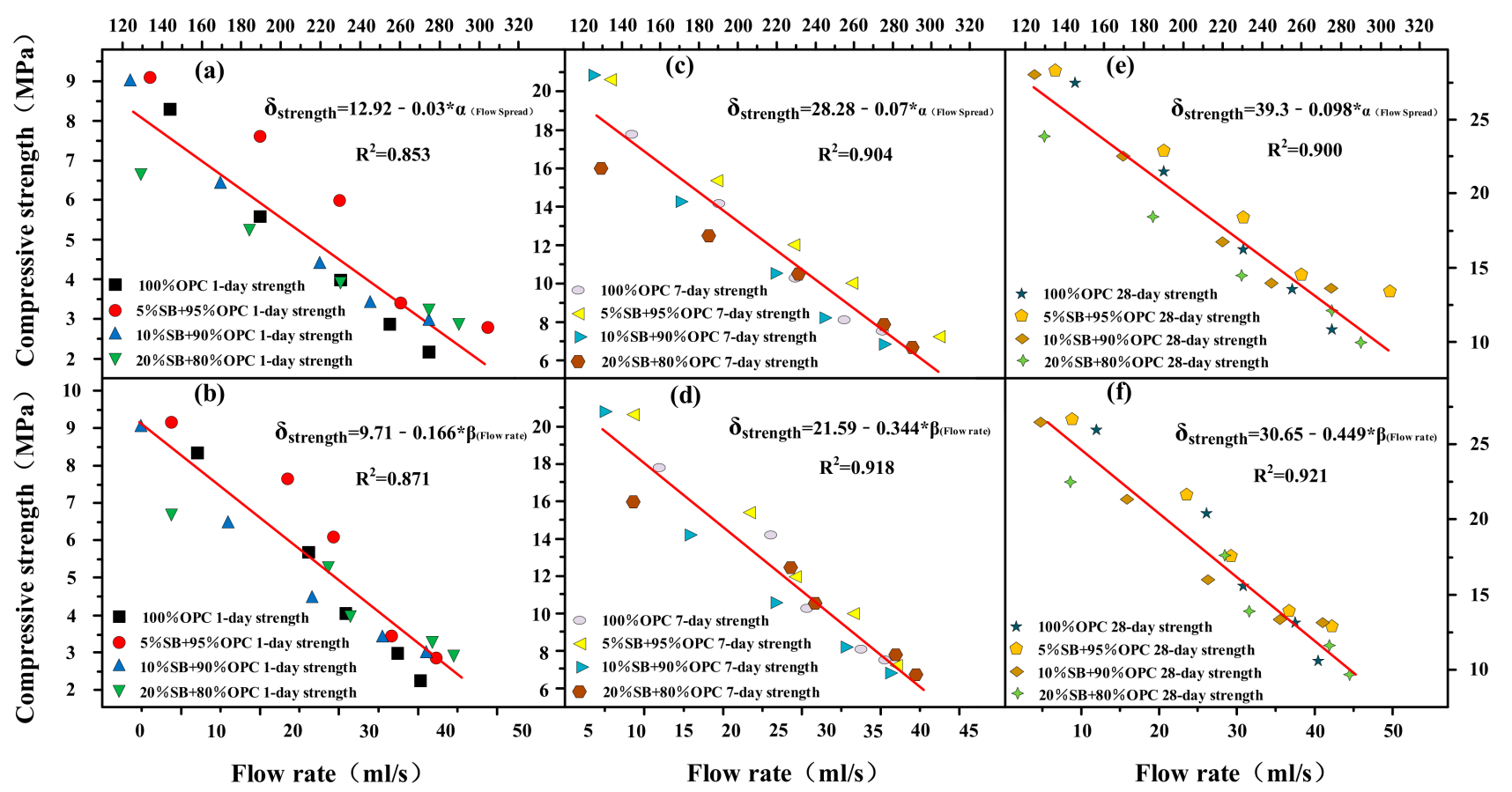

Figure 11. Flow rate and flow spread versus 1 day $(\mathbf{a}, \mathbf{b}), 7$ days $(\mathbf{c}, \mathbf{d})$, and 28 days $(\mathbf{e}, \mathbf{f})$ of compressive strength.

Yield stress $(\mathrm{Pa})$

Yield stress $(\mathbf{P a})$

Yield stress $(\mathrm{Pa})$

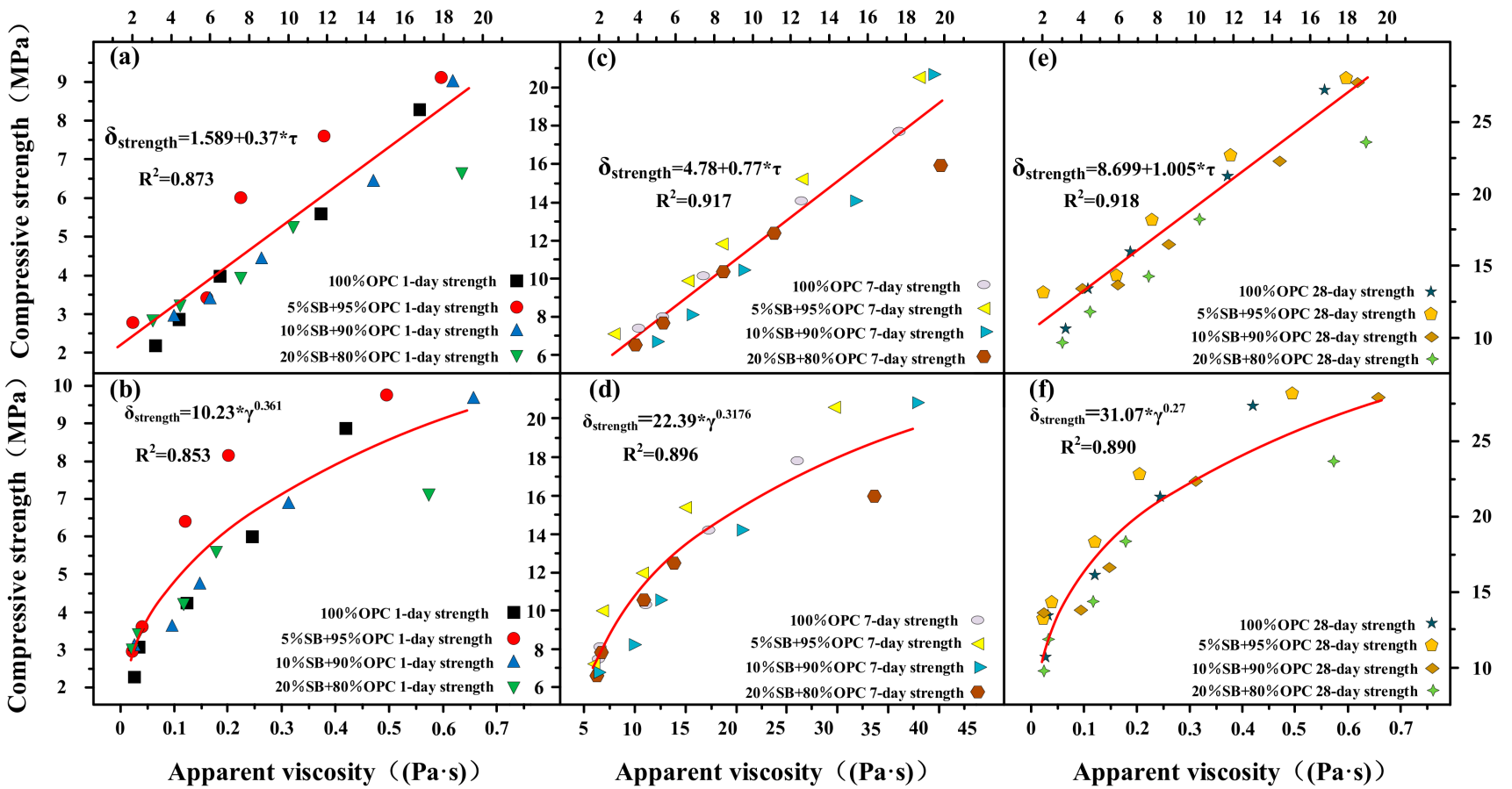

Figure 12. Apparent viscosity and yield stress versus 1 day $(\mathbf{a}, \mathbf{b}), 7$ days $(\mathbf{c}, \mathbf{d})$, and 28 days $(\mathbf{e}, \mathbf{f})$ of compressive strength. 
Flow spread ( $\mathrm{mm})$

Flow spread $(\mathbf{m m})$

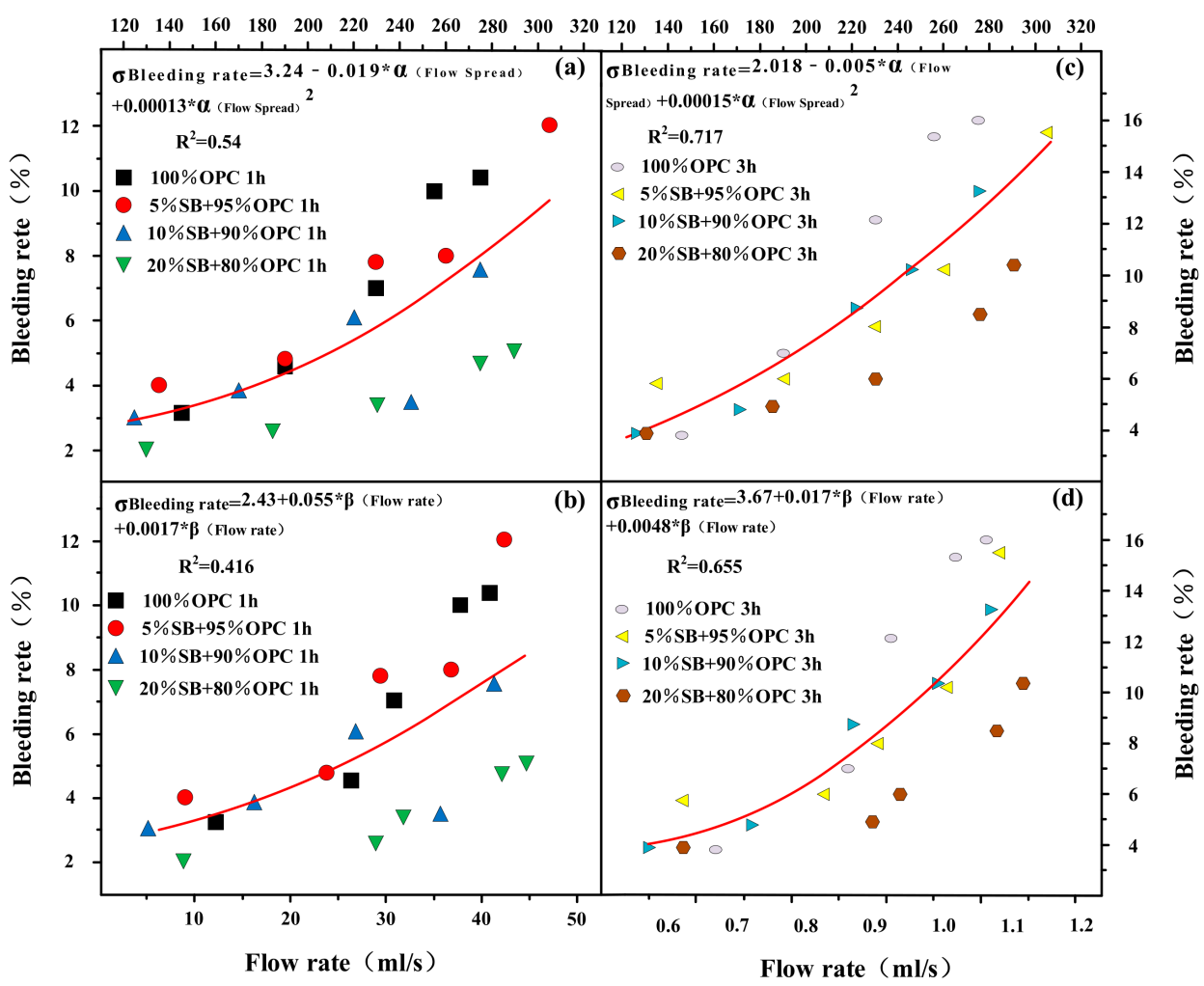

Figure 13. Flow rate and flow spread versus $1 \mathrm{~h}(\mathbf{a}, \mathbf{b})$ and $3 \mathrm{~h}(\mathbf{c}, \mathbf{d})$ bleeding rate.

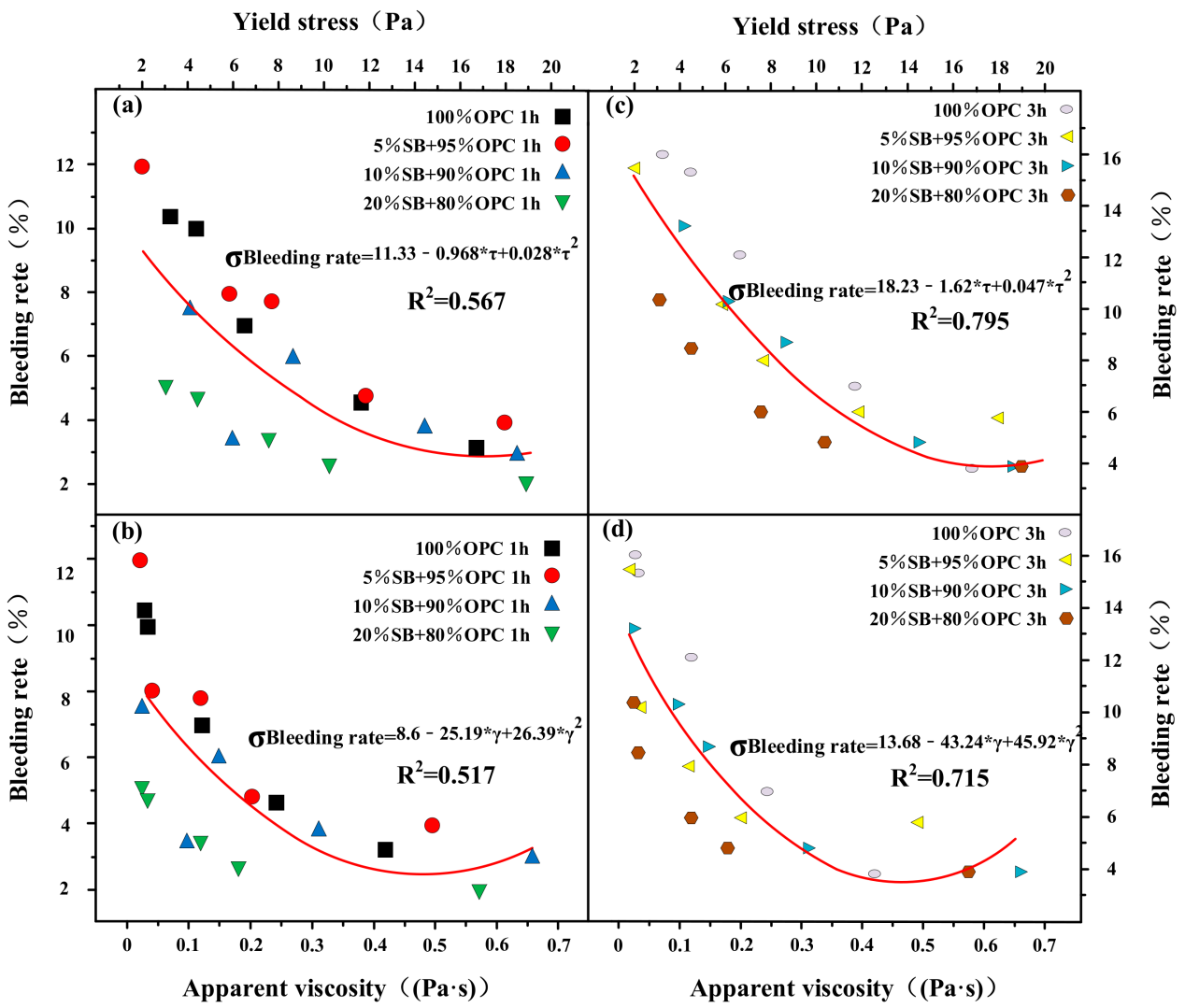

Figure 14. Apparent viscosity and yield stress versus $1 \mathrm{~h}(\mathbf{a}, \mathbf{b})$ and $3 \mathrm{~h}(\mathbf{c}, \mathbf{d})$ bleeding rate. 


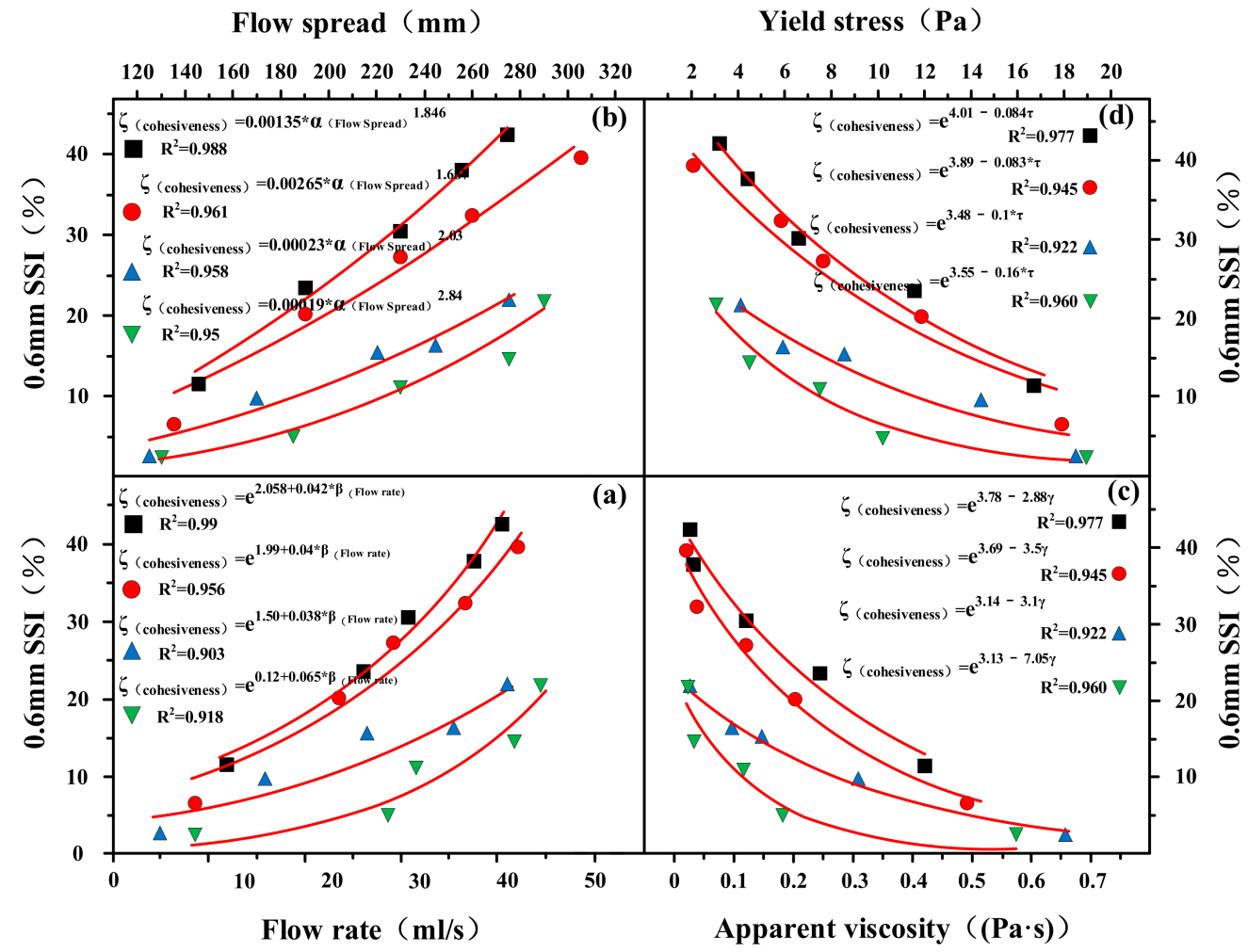

Figure 15. Flow rate (a), flow spread (b), apparent viscosity (c), and yield stress (d) versus cohesiveness.

The bleeding rate and cohesiveness are shown as functions of 1 day, 7 days, and 28 days of compressive strength for SB substitutions from 5\% to $20 \%$ in Figure 16a-f. The correlation between cohesiveness, compressive strength, and the bleeding rate was extremely poor. The changes in cohesiveness and bleeding rate did not significantly affect the compressive strength of cement paste containing SB.

\subsection{Mathematical Model Validation}

The empirical models with a good relationship established in Sections 3.1 and 3.2 are verified in this Section. The mathematical models that had a good correlation between WFT and the fresh properties were as follows: $\alpha_{\text {(Flow spread) }}=A+B^{*} W F T, \beta_{\text {(Flow rate) }}$ $=\mathrm{A}+\mathrm{B}^{*} \mathrm{WFT}+\mathrm{C}^{*} \mathrm{WFT}^{2}, \tau_{(\text {Yield stress })}=\mathrm{e}^{\left(\mathrm{A}+\mathrm{B}^{*} \mathrm{WFT}\right)}, \eta_{(\text {Apparent viscosity })}=\mathrm{Ae}^{\left(\mathrm{B}^{*} \mathrm{WFT}\right)}$ and $\delta_{(\text {Compressive strength })}=\mathrm{e}^{\left(\mathrm{A}+\mathrm{B}^{*} \mathrm{WFT}\right)}$. The mathematical models with good correlation between the fresh properties were as follows: $\alpha_{\text {(Flow spread) }}=A+B^{*} \tau_{\text {(Yield stress) }}, \beta_{\text {(Flow rate) }}=A+$ $B^{*} \tau($ Yield stress $), \alpha_{\text {(Flow spread })}=\mathrm{e}^{\left(\mathrm{A}+\mathrm{B}^{*} \eta(\text { Apparent viscosity })\right)}, \beta_{(\text {Flow rate })}=A \mathrm{e}^{\left(\mathrm{B}^{*} \eta(\text { Apparent viscosity })\right)}$, $\delta_{\text {(Compressive strength) }}=A+B^{*} \alpha_{(\text {Flow spread })}, \delta_{\text {(Compressive strength })}=A+B^{*} \beta_{\text {(Flow rate) }}$. $\delta_{(\text {Compressive strength })}=A+B^{*} \tau_{(\text {Yield stress })}$ and $\delta_{(\text {Compressive strength })}=A^{*} \eta_{\text {(Apparent viscosity })}{ }$. A mineral admixture (silicon powder) with a particle size and morphology similar to SB was selected here, as shown in Figure 17. The silicon powder was subjected to the same test procedure as SB with the same ratio and experimental conditions. The WFT, flow parameters, rheological parameters, apparent viscosity, yield stress, bleeding rate, and cohesiveness were obtained, and a regression analysis between these properties was performed to obtain the best fitting equation. Since it was an empirical model verification, the influence of silica fume on these properties is not described in detail here.

Figure 18a,b presents the mathematical empirical model verification with the W/CM ratio for different SF substitutions. The best fitting equations of the various parameters of the cement paste containing SF were in line with the empirical models obtained in Sections 3.1 and 3.2. All regression fitting coefficients $R^{2}$ were greater than 0.8 , and most of them were above 0.9 , which proves the rationality of the mathematical empirical models obtained. The purpose of model verification was to extend and apply the empirical model 
of a single system of cement paste containing SB to the entire cement paste system, which can provide a reference and theoretical basis for scholars to study the relationship between different fresh properties or mechanical properties of cement paste.

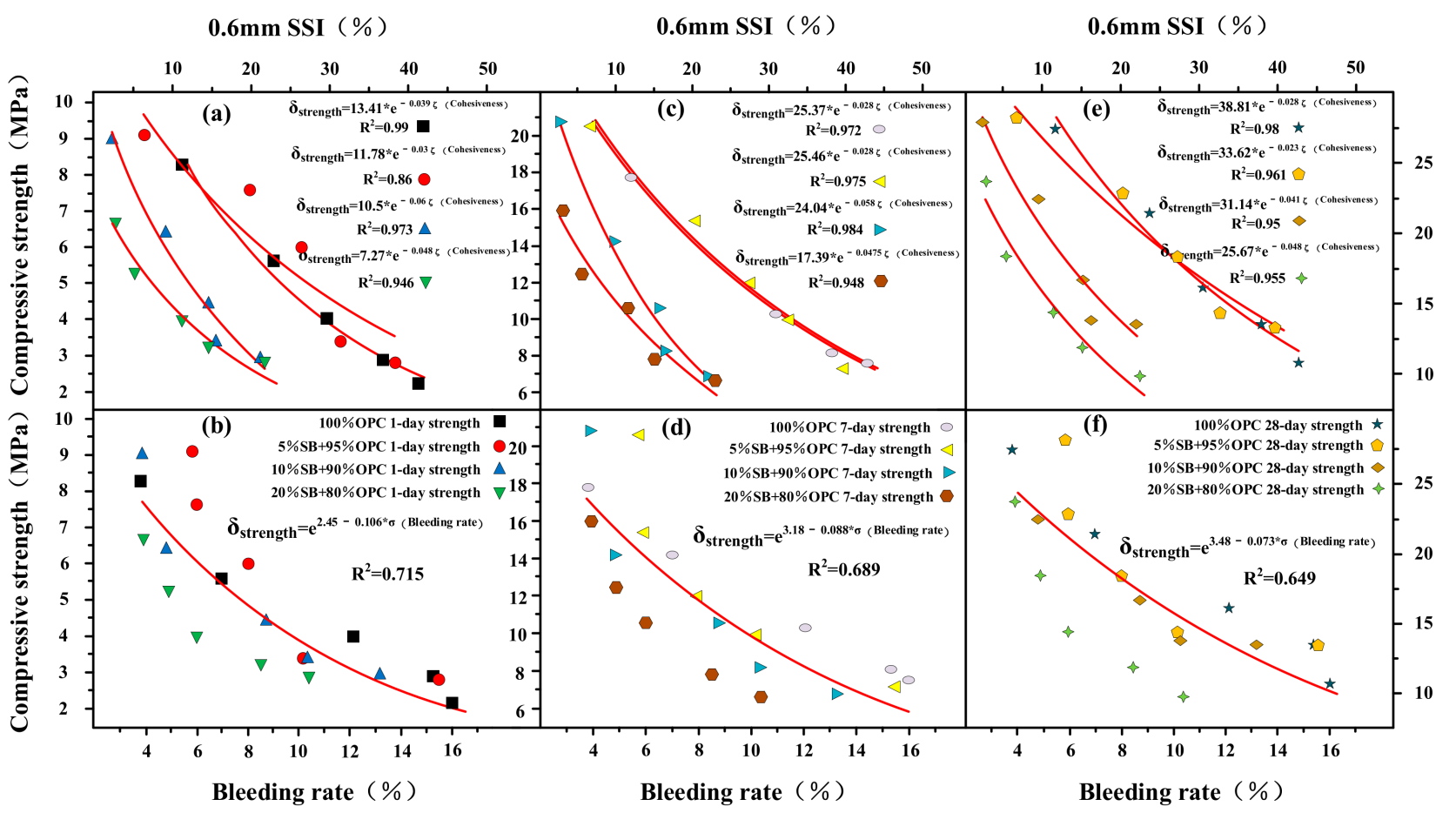

Figure 16. Bleeding rate and cohesiveness versus 1 day $(\mathbf{a}, \mathbf{b}), 7$ days $(\mathbf{c}, \mathbf{d})$, and 28 days $(\mathbf{e}, \mathbf{f})$ of compressive strength.
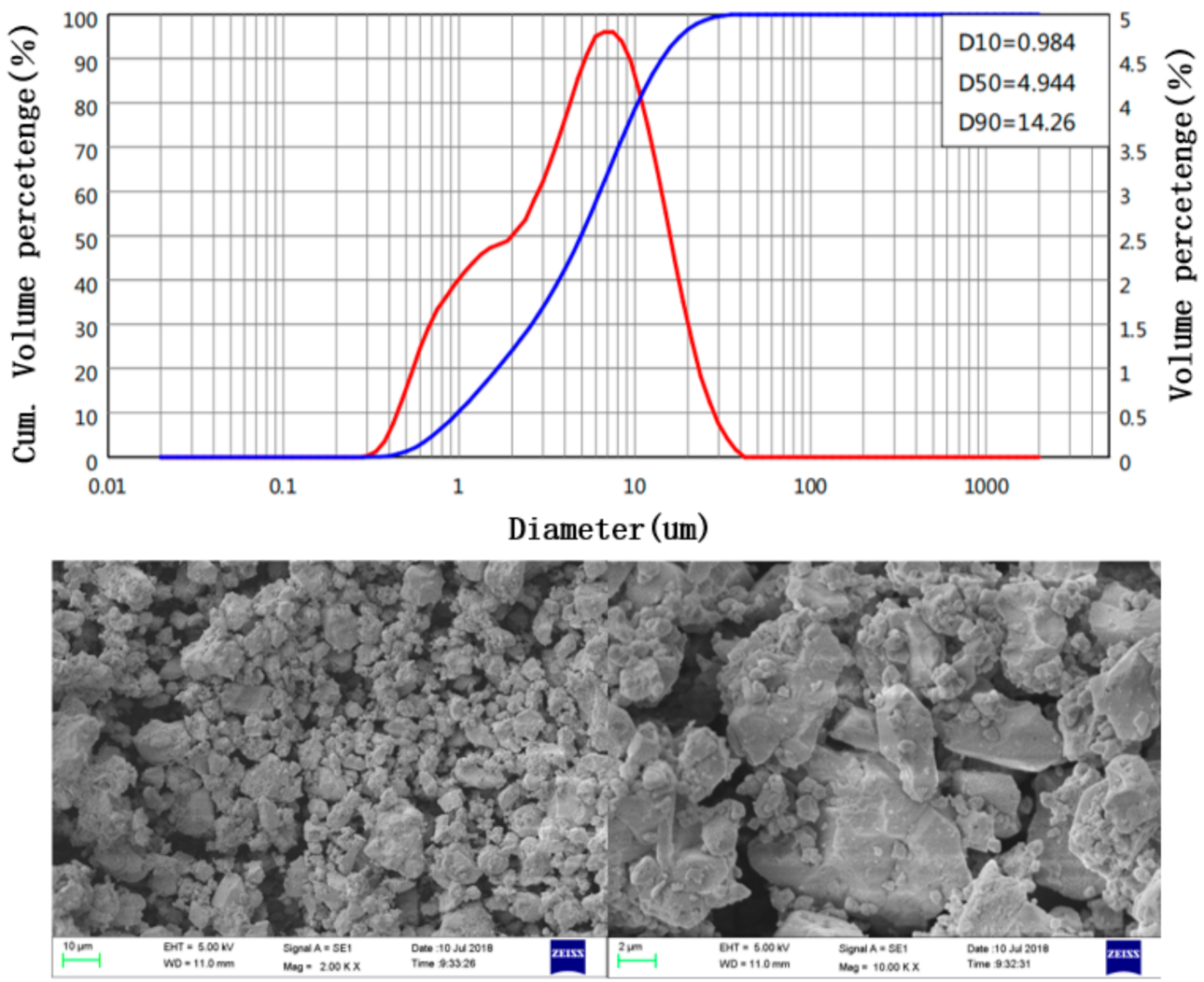

Figure 17. SEM photography and particle size distribution of silica powder. 


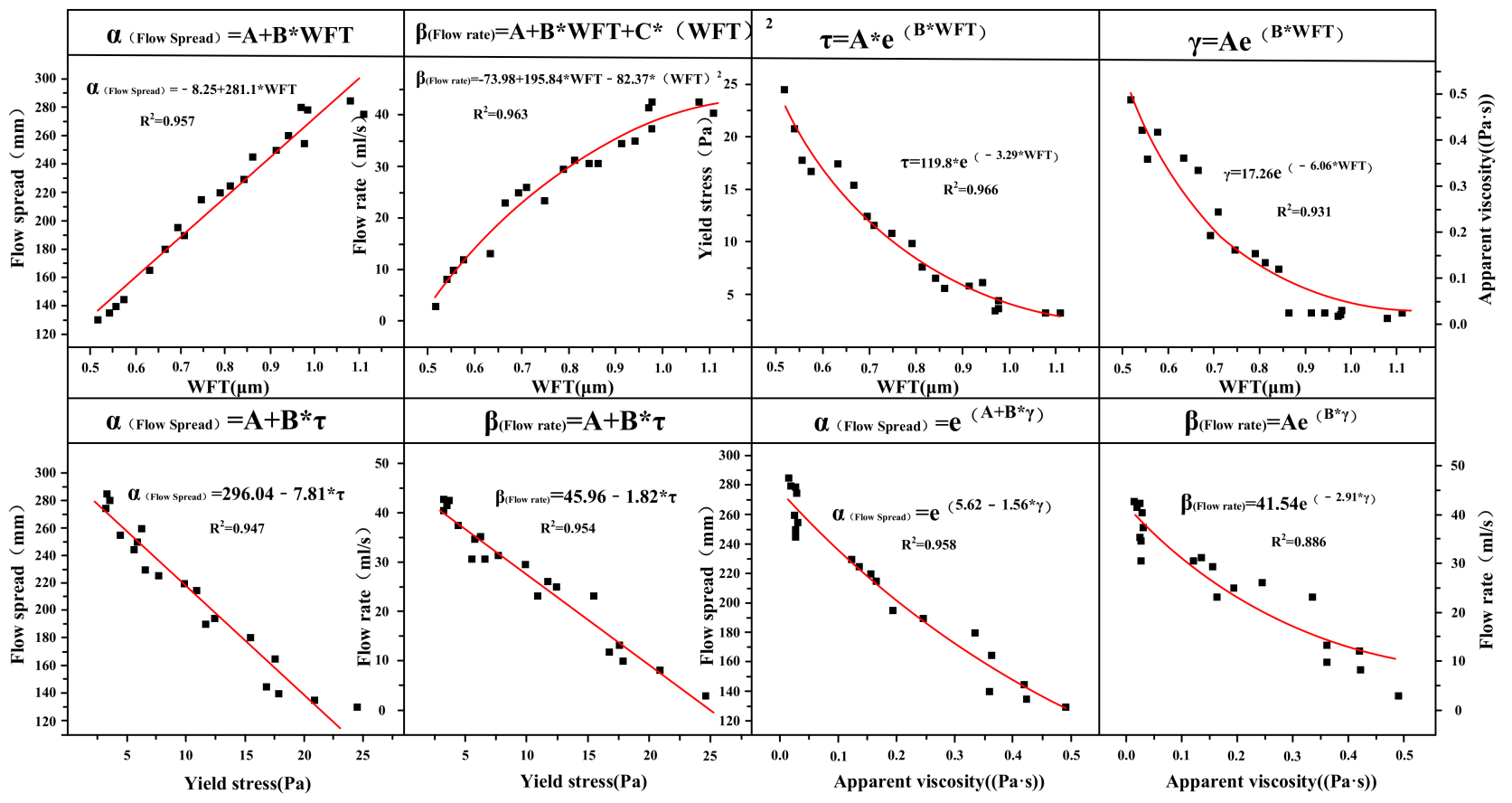

(a)

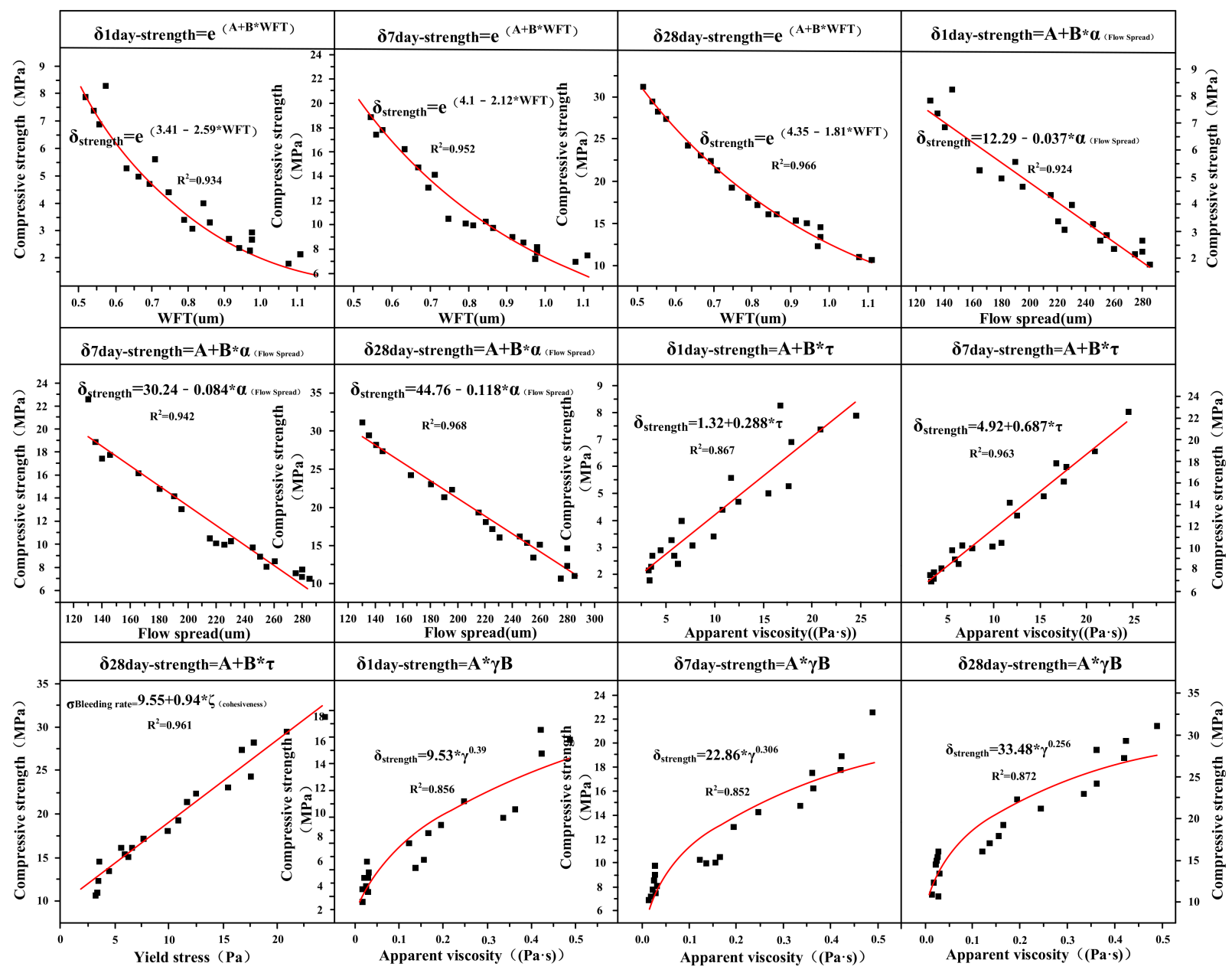

(b)

Figure 18. Mathematical empirical model verification $(\mathbf{a}, \mathbf{b})$ : (a) The mathematical empirical models between WFT and fresh properties; (b) The mathematical empirical models between WFT, fresh properties and compressive strength. 


\section{Conclusions}

Based on the above results, the main conclusions of this paper are as follows:

(1) The substitution of SB can effectively improve the segregation resistance and cohesiveness of paste; the maximum improvement rate relative to the control cement paste was $75.4 \%$ and $50.4 \%$, respectively. The $5 \%$ SB and $10 \%$ SB increased the 1 day, 7 days, and 28 days of compressive strength in the range of $1.2-25.7 \%$ but reduced the fluidity in the range of $4.1-68.7 \%$. The $20 \%$ SB reduced the 1 day, 7 days, and 28 days of compressive strength in the range of $1.1-13.9 \%$ but increased the fluidity in the range $1.8-11.8 \%$. The SB in the appropriate substitute content can meet the requirements of the fresh properties and compressive strength of the grouting material. As a new type of mineral admixture, SB can be used in the grouting field.

(2) The WFT had excellent correlation with rheological parameters, flow parameters, and compressive strength, and the regression coefficient $R^{2}$ exceeded 0.9. WFT was the most important factor that determined the rheological parameters, flow parameters, and compressive strength of cement paste containing SB. WFT and SB substitute content together determined the bleeding rate and cohesiveness. Among them, the correlation between bleeding rate and WFT increased with time. The mathematical models that had a good correlation between WFT and the fresh properties were as follows: $\alpha_{\text {(Flow spread) }}=\mathrm{A}+$ $B^{*} W F T, \beta_{(\text {Flow rate })}=A+B^{*} W F T+C^{*} W_{F T}^{2}, \tau_{(\text {Yield stress })}=e^{\left(A+B^{*} W F T\right)}, \eta_{(\text {Apparent viscosity })}=$ $\mathrm{Ae}^{\left(\mathrm{B}^{*} \mathrm{WFT}\right)}$ and $\delta_{(\text {Compressive strength })}=\mathrm{e}^{\left(\mathrm{A}+\mathrm{B}^{*} \mathrm{WFT}\right)}$.

(3) The mathematical models with good correlation between the fresh properties were as follows: $\alpha_{\text {(Flow spread) }}=\mathrm{A}+\mathrm{B}^{*} \tau_{(\text {Yield stress })}, \beta_{\text {(Flow rate })}=\mathrm{A}+\mathrm{B}^{*} \tau_{(\text {Yield stress })}, \alpha_{\text {(Flow spread })}$ $=\mathrm{e}^{\left(\mathrm{A}+\mathrm{B}^{*} \eta(\text { Apparent viscosity })\right)}, \beta_{(\text {Flow rate })}=A \mathrm{e}^{\left(\mathrm{B}^{*} \eta(\text { Apparent viscosity })\right)}, \delta_{(\text {Compressive strength })}=\mathrm{A}+$ $B^{*} \alpha_{\text {(Flow spread) }}, \delta_{\text {(Compressive strength) }}=A+B^{*} \beta_{\text {(Flow rate) }} . \delta_{(\text {Compressive strength) }}=A+B^{*} \tau_{\text {(Yield stress) }}$, $\delta_{(\text {Compressive strength })}=A^{*} \eta_{\text {(Apparent viscosity) }}{ }^{B}$. These empirical mathematical models were verified using silica fume with a similar morphology and particle size as $\mathrm{SB}$, which successfully extended the empirical mathematical model to the entire field of cement-basted materials for application.

Author Contributions: Conceptualization: H.L.; Methodology: H.L.; writing original draft: H.L.; writing review and editing: H.F.; investigation: H.F.; supervision: Z.T.; funding acquisition: Z.T. All authors have read and agreed to the published version of the manuscript.

Funding: This study was financially supported by the National Natural Science Fund of China [grant numbers 51909072 and 51879094] and the Fundamental Research Funds for the Central Universities [grant number B210202016]. The author is grateful to Tingshuang Li for supporting this study.

Institutional Review Board Statement: Not applicable.

Informed Consent Statement: Not applicable.

Data Availability Statement: Data Sharing is not applicable.

Conflicts of Interest: The authors declare no conflict of interest.

\section{References}

1. Dandautiya, R.; Singh, A.P. Utilization potential of fly ash and copper tailings in concrete as partial replacement of cement along with life cycle assessment. Waste Manag. 2019, 99, 90-101. [CrossRef] [PubMed]

2. Shwekat, K.; Wu, H.-C. Benefit-cost analysis model of using class F fly ash-based green cement in masonry units. J. Clean. Prod. 2018, 198, 443-451. [CrossRef]

3. Wang, J.; Wang, Y.; Sun, Y.; Tingley, D.D.; Zhang, Y. Life cycle sustainability assessment of fly ash concrete structures. Renew. Sustain. Energy Rev. 2017, 80, 1162-1174. [CrossRef]

4. Güllü, H.; Cevik, A.; Al-Ezzi, K.M.A.; Gülsan, M.E. On the rheology of using geopolymer for grouting: A comparative study with cement-based grout included fly ash and cold bonded fly ash. Constr. Build. Mater. 2019, 196, 594-610. [CrossRef]

5. Li, Z.; Zhang, J.; Li, S.; Gao, Y.; Liu, C.; Qi, Y. Effect of different gypsums on the workability and mechanical properties of red mud-slag based grouting materials. J. Clean. Prod. 2020, 245, 118759. [CrossRef]

6. El-Wafa, M.A.; Fukuzawa, K. Optimization of Alkali-Activated Municipal Slag Composite Performance by Substituting Varying Ratios of Fly Ash for Fine Aggregate. Materials 2021, 14, 6299. [CrossRef] [PubMed] 
7. Gradinaru, C.M.; Serbanoiu, A.A.; Muntean, R.; Serbanoiu, B.V. The Synergy between Bio-Aggregates and Industrial Waste in a Sustainable Cement Based Composite. Materials 2021, 14, 6158. [CrossRef] [PubMed]

8. Gu, C.; Yao, J.; Yang, Y.; Huang, J.; Ma, L.; Ni, T.; Liu, J. The Relationship of Compressive Strength and Chemically Bound Water Content of High-Volume Fly Ash-Cement Mortar. Materials 2021, 14, 6273. [CrossRef] [PubMed]

9. Muhammad, A.; Thienel, K.-C.; Sposito, R. Suitability of Blending Rice Husk Ash and Calcined Clay for the Production of Self-Compacting Concrete: A Review. Materials 2021, 14, 6252. [CrossRef] [PubMed]

10. Vogt, O.; Ukrainczyk, N.; Koenders, E. Effect of Silica Fume on Metakaolin Geopolymers' Sulfuric Acid Resistance. Materials 2021, 14, 5396. [CrossRef] [PubMed]

11. Cao, W.; Liu, S.; Feng, Z. Comparison of performance of stone matrix asphalt mixtures using basalt and limestone aggregates. Constr. Build. Mater. 2013, 41, 474-479. [CrossRef]

12. Dobiszewska, M.; Schindler, A.K.; Pichór, W. Mechanical properties and interfacial transition zone microstructure of concrete with waste basalt powder addition. Constr. Build. Mater. 2018, 177, 222-229. [CrossRef]

13. Li, P.P.; Yu, Q.L.; Brouwers, H.J.H. Effect of coarse basalt aggregates on the properties of Ultra-high Performance Concrete (UHPC). Constr. Build. Mater. 2018, 170, 649-659. [CrossRef]

14. Ponzi, G.G.D.; Santos, V.H.J.M.d.; Martel, R.B.; Pontin, D.; e Stepanha, A.S.d.G.; Schütz, M.K.; Menezes, S.C.; Einloft, S.M.O.; Vecchia, F.D. Basalt powder as a supplementary cementitious material in cement paste for CCS wells: Chemical and mechanical resistance of cement formulations for $\mathrm{CO}_{2}$ geological storage sites. Int. J. Greenh. Gas Control 2021, 109, 103337. [CrossRef]

15. Matykiewicz, D.; Barczewski, M.; Michałowski, S. Basalt powder as an eco-friendly filler for epoxy composites: Thermal and thermo-mechanical properties assessment. Compos. Part. B Eng. 2019, 164, 272-279. [CrossRef]

16. Laibao, L.; Yunsheng, Z.; Wenhua, Z.; Zhiyong, L.; Lihua, Z. Investigating the influence of basalt as mineral admixture on hydration and microstructure formation mechanism of cement. Constr. Build. Mater. 2013, 48, 434-440. [CrossRef]

17. Saraya, M.E.-S.I. Study physico-chemical properties of blended cements containing fixed amount of silica fume, blast furnace slag, basalt and limestone, a comparative study. Constr. Build. Mater. 2014, 72, 104-112. [CrossRef]

18. Kostrzewa-Demczuk, P.; Stepien, A.; Dachowski, R.; Krugiełka, A. The use of basalt powder in autoclaved brick as a method of production waste management. J. Clean. Prod. 2021, 320, 128900. [CrossRef]

19. Guo, Y.; Zhang, T.; Wei, J.; Yu, Q.; Ouyang, S. Evaluating the distance between particles in fresh cement paste based on the yield stress and particle size. Constr. Build. Mater. 2017, 142, 109-116. [CrossRef]

20. Kwan, A.K.H.; Chen, J.J. Adding fly ash microsphere to improve packing density, flowability and strength of cement paste. Powder Technol. 2013, 234, 19-25. [CrossRef]

21. Kwan, A.K.H.; Fung, W.W.S. Effects of SP on flowability and cohesiveness of cement-sand mortar. Constr. Build. Mater. 2013, 48, 1050-1057. [CrossRef]

22. Kwan, A.K.H.; McKinley, M. Effects of limestone fines on water film thickness, paste film thickness and performance of mortar. Powder Technol. 2014, 261, 33-41. [CrossRef]

23. Li, Y.; Kwan, A.K.H. Ternary blending of cement with fly ash microsphere and condensed silica fume to improve the performance of mortar. Cem. Concr. Compos. 2014, 49, 26-35. [CrossRef]

24. Mehdipour, I.; Khayat, K.H. Elucidating how particle packing controls rheology and strength development of dense cementitious suspensions. Cem. Concr. Compos. 2019, 104, 103413. [CrossRef]

25. Wong, H.H.C.; Kwan, A.K.H. Packing density of cementitious materials: Part 1-measurement using a wet packing method. Mater. Struct. 2007, 41, 689-701. [CrossRef]

26. Hajime, O. Masahiro O, Self-Compacting Concrete. J. Adv. Concr. Technol. 2003, 1, 5-15.

27. Sun, X.; Liu, H.; Tian, Z.; Ma, Y.; Wang, Z.; Fan, H. Feasibility and economic evaluation of grouting materials containing binary and ternary industrial waste. Constr. Build. Mater. 2021, 274, 122021. [CrossRef]

28. Chen, J.J.; Fung, W.W.S.; Kwan, A.K.H. Effects of CSF on strength, rheology and cohesiveness of cement paste. Constr. Build. Mater. 2012, 35, 979-987. [CrossRef]

29. Chen, J.J.; Li, L.G.; Ng, P.L.; Kwan, A.K.H. Effects of superfine zeolite on strength, flowability and cohesiveness of cementitious paste. Cem. Concr. Compos. 2017, 83, 101-110. [CrossRef]

30. Kwan, A.K.H.; Wong, H.H.C. Packing density of cementitious materials: Part 2-packing and flow of OPC + PFA + CSF. Mater. Struct. 2007, 41, 773-784. [CrossRef]

31. Kwan, A.K.H.; Wong, H.H.C. Effects of packing density, excess water and solid surface area on flowability of cement paste. Adv. Cem. Res. 2008, 20, 1-11. [CrossRef]

32. Chen, J.J.; Kwan, A.K.H. Superfine cement for improving packing density, rheology and strength of cement paste. Cem. Concr. Compos. 2012, 34, 1-10. [CrossRef]

33. Perrot, A.; Lecompte, T.; Khelifi, H.; Brumaud, C.; Hot, J.; Roussel, N. Yield stress and bleeding of fresh cement pastes. Cem. Concr. Res. 2012, 42, 937-944. [CrossRef]

34. Liu, H.; Sun, X.; Du, H.; Lu, H.; Ma, Y.; Shen, W.; Tian, Z. Effects and threshold of water film thickness on multi-mineral cement paste. Cem. Concr. Compos. 2020, 112, 103677. [CrossRef]

35. Peng, H.; Zhan, Z.; Xie, L.; She, J.; Liu, H. Influence of marble pow der or granite pow der on rheological properties of cement paste. Concrete 2018, 346, 92-96. 
36. Peng, Y.; Lauten, R.A.; Reknes, K.; Jacobsen, S. Bleeding and sedimentation of cement paste measured by hydrostatic pressure and Turbiscan. Cem. Concr. Compos. 2017, 76, 25-38. [CrossRef]

37. Liu, S.; Zhang, T.; Guo, Y.; Wei, J.; Yu, Q. Effects of SCMs particles on the compressive strength of micro-structurally designed cement paste: Inherent characteristic effect, particle size refinement effect, and hydration effect. Powder Technol. 2018, 330, 1-11. [CrossRef]

38. Cyr, M.; Lawrence, P.; Ringot, E. Efficiency of mineral admixtures in mortars: Quantification of the physical and chemical effects of fine admixtures in relation with compressive strength. Cem. Concr. Res. 2006, 36, 264-277. [CrossRef]

39. Yajun, J.; Cahyadi, J.H. Effects of densified silica fume on microstructure and compressive strength of blended cement pastes. Cem. Concr. Res. 2003, 33, 1543-1548. [CrossRef] 